\title{
Metal-based Inkjet Inks for Printed Electronics
}

\author{
Alexander Kamyshny ${ }^{1}$, Joachim Steinke ${ }^{2}$ and Shlomo Magdassi ${ }^{1, *}$ \\ ${ }^{I}$ Casali Institute of Applied Chemistry, Institute of Chemistry, The Hebrew University of Jerusalem, Jerusalem 91904, \\ Israel \\ ${ }^{2}$ Department of Chemistry and Centre for Plastic Electronics, Imperial College London, South Kensington Campus, \\ London SW7 2AZ, UK
}

\begin{abstract}
A review on applications of metal-based inkjet inks for printed electronics with a particular focus on inks containing metal nanoparticles, complexes and metallo-organic compounds. The review describes the preparation of such inks and obtaining conductive patterns by using various sintering methods: thermal, photonic, microwave, plasma, electrical, and chemically triggered. Various applications of metal-based inkjet inks (metallization of solar cell, RFID antennas, OLEDs, thin film transistors, electroluminescence devices) are reviewed.
\end{abstract}

Keywords: Metal nanoparticles, metallo-organic compounds, conductive inks, printed electronics, metallization, sintering, solar cells, RFID, OLEDs, thin film transistors.

\section{INTRODUCTION}

An important element of all electronic devices is the conductive structure, which is formed by depositing metal that connects various components, the "electric wiring". Conventional electronic systems are traditionally fabricated using photolithography, a complex and time consuming multiple steps process that requires expensive facilities. Moreover, the photolithographic process generates large volumes of hazardous waste, which damages the environment $[1,2]$. Vacuum deposition techniques for the fabrication of electronic devices are not as costly as photolithography, but are energy intensive and give patterns with low resolution [1]. Metal deposition by electroless plating, being simpler than photolithography, is rather slow, usually does not enable high resolution, requires the use of environmentally undesirable chemicals, and results also in formation of a large amounts of waste [3]. A better alternative to these procedures is screen printing of thick films using polymer pastes containing micron-sized metal flakes (usually $\mathrm{Ag}$ or Ag alloys). Although this procedure involves only two steps: printing and curing the obtained pattern by thermal treatment, it is expensive due to the rather large amount of ink required relative to the yield [1] and is suitable only for nonfragile substrates due to the contact-mode of printing. One more approach to deposition of conductive patterns is a filamentary printing: extrusion of highly concentrated polymerstabilized silver ink (solids loading between 70 to $85 \mathrm{wt} \%$ ) through a cylindrical nozzle $[4,5]$.

The global market demand for high quality and low cost electronic components requires innovative fabrication

*Address correspondence to this author at the Casali Institute of Applied Chemistry, Institute of Chemistry, The Hebrew University of Jerusalem, Jerusalem 91904, Israel; Tel: +972-2-6584967; Fax: +972-2-6584350;

E-mail: magdassi@cc.huji.ac.il techniques that are both faster and cheaper compared to traditional production methods. In this regard, inkjet printing with the use of inks based on metal nanoparticles (NPs), metallo-organic decomposition ink (MOD) based on metallo-organic complexes (MC) or salts of various metals is a very attractive low-cost technology for direct metallization.

Inkjet printing, which is widely used in office and home printers, is a non-impact dot-matrix digital printing technology, in which droplets of ink are jetted from a small orifice in a printhead, directly to a specified position on a substrate, as a result of pressure developed after an electronic signal has been sent to the printhead to create an image. Today the majority of inkjet printers are based on the drop-on-demand (DOD) methods (Fig. 1): thermal, piezoelectric, electrostatic or acoustic generation of droplets [6]. Most, if not all DOD printers on the market today use either thermal or piezoelectric printheads.

In the last two decades, inkjet printing, which has seen commercial success since the late 1970 s, has grown to be an important topic in scientific research and technology [7]. The main advantages of inkjet printing compared to other deposition methods are one-step processing, cheap and compact equipment, and applicability to various substrates $[1,2,8]$.

In addition to conventional graphic applications, inkjet printing has been adapted for patterning various functional materials such as organic light emitting diodes (OLED) [9], transistors, integrated circuits, conducting polymer devices, structural polymers and ceramics [7], biomaterials, and even printed scaffolds for growth of living tissues [7, 10], as well as for building complicated 3D objects [11] and microelectromechanical systems (MEMS) [12]. Applied to printed electronics, inkjet printing enables patterning with high resolution: line and space dimensions can be as small as 10$20 \mu \mathrm{m}$, that is at least five times better than the current resolution of screen printing $[13,14]$. 


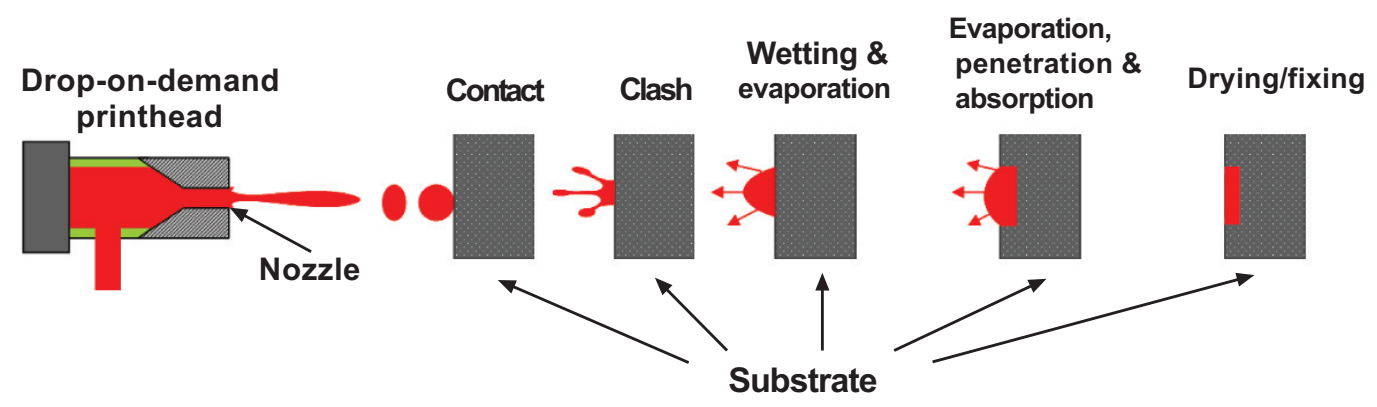

Fig. (1). Schematic presentation of the DOD inkjet printing process.

In the electronic industry, manufacturing electronic devices such as flexible displays, radio frequency identification (RFID) tags, sensors, OLEDs, PV devices including solar cells (SC), batteries, and printed circuit boards (PCB) by inkjet printing of conductive inks can provide low-cost means of manufacturing large-area electronics on a wide range of substrates (paper, polymers, glass, metals, ceramics etc.) and is attracting tremendous interest [1, 2, 15-19].

\section{COMPOSITION OF METAL-BASED INKS: RE- QUIREMENTS AND CHALLENGES}

A major challenge in applying inkjet techniques for the deposition of functional materials is the formulation of suitable inks [20]. The basic requirements for metal-based inks are similar to those of standard inkjet inks, but in addition, they should provide good electrical conductivity of the printed pattern. The ink should demonstrate compatibility with the substrate and good printability and resolution with minimum printer maintenance [1]. In addition, the ink should be processable (annealing, curing) at temperatures below 150 ${ }^{\circ} \mathrm{C}$, or better $120{ }^{\circ} \mathrm{C}$ to be compatible with flexible substrates such as polyethylene terephthalate (PET).

Both conductive and non-conductive inkjet inks are comprised of a liquid vehicle (water or an organic solvent), which determines the basic properties of the ink, and a dispersed or dissolved component providing the desired functionality. Ink formulations that employ nanoparticles or dissolved metal precursors of highly conductive metals such as $\operatorname{Ag}\left(\sigma=6.3 \cdot 10^{7} \Omega^{-1} \cdot \mathrm{m}^{-1}\right), \mathrm{Cu}\left(\sigma=5.96 \cdot 10^{7} \Omega^{-1} \cdot \mathrm{m}^{-1}\right), \mathrm{Au}(\sigma=$ $\left.4.42 \cdot 10^{7} \Omega^{-1} \cdot \mathrm{m}^{-1}\right)$, and Al $\left(\sigma=3.78 \cdot 10^{7} \Omega^{-1} \cdot \mathrm{m}^{-1}\right)$ offer a clear advantage over other formulations. In nanoparticle-based inks, the metallic dispersion in the ink should be stable to aggregation and precipitation in order to obtain ink with reproducible performance. Therefore, addition of a stabilizing agent, which is usually a polymeric material, is required. Viscosity, surface tension, and wettability are also critical characteristics of the conductive ink formulation [20]. They affect printing quality, since they determine drop size, drop placement accuracy, satellite formation, and wetting of the substrate $[1,7]$. In the case of piezoelectric print heads, the ink viscosity should be in the range of $8-15 \mathrm{cP}$, while thermal print heads require viscosity below $3 \mathrm{cP}$ [7]. For surface tension, the typical values for industrial printheads are in the range of 25-35 dyne/cm. Ink-jet ink formulations may also include a binder (usually a resin), which provides adhesion of the printed pattern to the substrate $[1,7]$.

However, after drying of the ink, the presence of stabilizing agents and other components of the ink composition prevents the formation of continuous interconnected phase be- tween metal particles in the printed pattern due to formation of insulating layers between the particles, resulting in low electrical conductivity. To obtain a conductive pattern, an additional, post-printing treatment is usually required.

One more challenge, which arises while using non-noble metals is rapid oxidation of the metal NPs in the ink formulations at ambient conditions, as well as oxidation of metal in patterns printed with the use of MC-based inks.

At present, most conductive inks are based on Ag NPs, since $\mathrm{Ag}$ possesses the highest electrical conductivity among metals and is resistant to oxidation. Such inks are already commercially available (at least 10 companies in the United States, Japan, Korea and Israel produce Ag-based conductive inks). The main challenge in replacing $\mathrm{Ag}$ by the much cheaper metals, $\mathrm{Cu}$ and $\mathrm{Al}$, is in avoiding their oxidation at ambient conditions, which usually requires rather sophisticated reaction conditions - the use of hydrocarbon solvents, low precursor concentration and inert atmosphere [19, 2127]. For example, $\mathrm{Al}$ undergoes rapid oxidation in air $(\sim 100$ picoseconds) with formation of a dense thin amorphous $\mathrm{Al}_{2} \mathrm{O}_{3}$ layer $(2-6 \mathrm{~nm})[28,29]$ that results in loss of electrical conductivity and makes aluminum inapplicable for conductive ink formulations. Oxidation of $\mathrm{Cu}$ NPs is less rapid compared to Al NPs, especially in the presence of an excess of reducing agent, as we reported recently [19, 24]. This enables formulations with freshly prepared $\mathrm{Cu}$ NPs in order to obtain NPs with long-term stability at ambient conditions [19, 24, 25], and Cu NP-based inkjet inks are now commercially available. As to MC-based inks, the only examples of commercial inks are inks based on organosilver compounds, which are produced by Gwent Electronic Materials Ltd. (UK) and by InkTec (Korea).

\section{RESISTIVITY AND SINTERING}

\subsection{Electrical Resistivity}

Electrical resistivity is a value that describes the true performance of a conductor after the printing and sintering processes, and is defined as follows:

$\rho=\mathrm{R} \cdot \mathrm{A} / \mathrm{L}$

where $\rho$ is resistivity in ohm meter $(\Omega \cdot \mathrm{m})$, or micro ohm centimeter $(\mu \Omega \cdot \mathrm{cm}), R$ is the measured resistance of a conductor $(\Omega), A$ is its cross-sectional area, and $L$ is the length [1]. Conductivity is the reciprocal of resistivity:

$\sigma=1 / \rho=L / R \cdot A$

and is measured in Siemens $\left(\mathrm{S}=\Omega^{-1}\right)$ per meter $\left(\mathrm{S} \cdot \mathrm{m}^{-1}\right)$. 
If the length and width of the measured sample are equal, then $R$ is referred to as "sheet resistance", $\mathrm{R}\left(\Omega^{-1}\right)$ and Eq. 1 simplifies to

$\rho=\mathrm{R} \cdot \mathrm{h}$

where $h$ is the thickness of the printed layer.

Since the printed pattern typically contains voids and/or non-conductive material, and the conductive path is not completely unidirectional, $A$ is larger than the actual conductive area, and $L$ is shorter than the actual conductive path length. Therefore, the calculated $\rho$ may differ from that measured, and thus represents only the proportionality constant relating the measured resistance to overall sample geometry, rather than an inherent property of the conductive portion of the material.

An alternative method of calculating the resistivity of printed patterns, in which only the solid conductive crosssectional area $A_{s}$ is considered, is a mass-based method:

$$
\rho_{s}=R \cdot A_{s} / L
$$

where $A_{s}$ is the equivalent conductive cross-sectional area of the sample and is related to the mass of the conductive fraction of the pattern $\left(m_{c}\right)$ and density $\left(d_{s}\right)$ of the solid conductive material (e.g., $10.45 \mathrm{~g} / \mathrm{cm}^{3}$ for silver) [1]:

$$
A_{s}=\left(m_{c} / d_{s}\right) / L
$$

\subsection{Sintering}

To form a conductive printed pattern, potentially conductive particles must be sintered to create continuous connectivity and thus percolated paths. Sintering is a process of welding particles together at temperatures below their melting point [1].

The conventional approach to sinter metal NPs is heating. Because of the high surface-to-volume ratio (e.g., typically, for spherical metal NPs with diameter of $3 \mathrm{~nm}$ about half of the atoms are located at the surface, while for $10 \mathrm{~nm}$ particles this value is about $15 \%$ ) they are characterized by decreased melting temperatures. For example, for silver and gold particles with a diameter of $2.5 \mathrm{~nm}$, a reduction in melting point is estimated to be around $400{ }^{\circ} \mathrm{C}$ and $500{ }^{\circ} \mathrm{C}$, respectively [30], the melting temperature of $1.5 \mathrm{~nm}$ gold particles was experimentally found to be as low as $380^{\circ} \mathrm{C}$ (melting point of bulk gold is $1063{ }^{\circ} \mathrm{C}$ ) [31]. Even for particles of $20 \mathrm{~nm}$ diameter, the melting point was found to be noticeably lower than that of the bulk metal [31]. Such a depression of the melting point makes metallic NPs much "softer" than large particles, and enhanced self-diffusion of the metal atoms induces initial neck formation between NPs thus causing the bonding of particles to each other followed by grain growth and shrinkage with formation of a bulk phase [1].

For MC and metallo-organic compounds, three mechanisms of sintering are possible:

1. The coordinating ligand is displaced from the complex upon contact with the substrate surface and the remaining ligand-metal fragment coordinates to the surface via the metal, subsequently the metal ion is reduced to metal and the ligand is expelled at the same time.
2. The metal precursor decomposes in the liquid-phase and produces metal prior to approaching the substrate. Individual atoms or clusters will ultimately precipitate onto the substrate surface, leaving the ligands behind in the solution, or if the ligands are volatile, they will evaporate from the ink.

3. If the ligands around the metal are chosen in such a way that decomposition of the metal precursor leads to the formation of ligand-coated metal nanoclusters (metal NPs) then the scenario becomes equivalent to the sintering of metal NPs.

\subsection{Methods of Sintering}

The sintering step can be achieved by exposure of the printed pattern to heat (thermal sintering), intense light (photonic sintering), microwave radiation, plasma, by applying an electrical voltage, and by chemical agent at room temperature (RT sintering). The focus in the development of various sintering methods is to avoid destructive heating of polymeric substrates, such as PET and polycarbonate, which are the most common flexible substrates and therefore are of great economical importance for printed plastic electronics.

\subsubsection{Thermal Sintering}

Heating of printed patterns results in evaporation of liquid and forces the particles to become close to each other. The main problem for achieving high conductivity is the presence of a residual insulating layer composed of organic stabilizer molecules that surrounds the particles. Usually, heating to a high temperature $\left(300{ }^{\circ} \mathrm{C}\right.$ and above) is required to burn-out all organic contaminants, and very rarely the conductive patterns are obtained at temperatures as low as $150^{\circ} \mathrm{C}[12,13]$. Sintering of MCs can be achieved by flameassisted chemical vapor deposition (FACVD) [32] or by coating the substrate at room temperature followed by high temperature annealing (sometimes in an atmosphere of a reducing agent) [33].

\subsubsection{Photonic Sintering}

The mechanism of photonic sintering of metal NPs and $\mathrm{MC}$ is similar to that of thermal sintering. Light absorption by the printed metallic layer results in its heating followed by evaporation of liquid, and sintering [16, 34, 35]. Local laser heating (e.g., Ar ion laser, 488 and $514 \mathrm{~nm}$ ) is advantageous due to a reduction in the heat-affected zone and the more effective, selective energy transfer and thus especially relevant for application in plastic electronics. The basic concept of local laser sintering is shown in Fig. (2) [16]. Laser sintering of a printed Au layer resulted in resistivity only 6 times greater than that of bulk $\mathrm{Au}$ [35].

\subsubsection{Microwave Sintering}

A new flash microwave sintering process was recently developed by Schubert et al. [18, 36]. Metals can be fast sintered by microwave radiation, but they have a very small penetration depth: the penetration depth at $2.54 \mathrm{GHz}$ for $\mathrm{Ag}$, $\mathrm{Au}$, and $\mathrm{Cu}$ ranges from 1.3 to $1.6 \mu \mathrm{m}$. Microwave sintering of metals is successful only if the dimension of the object perpendicular to the plane of incidence is of the same order as the penetration depth. Since inkjet printed conductive tracks fulfill this requirement, it is expected that this technology will be adapted for industrial manufacturing. 

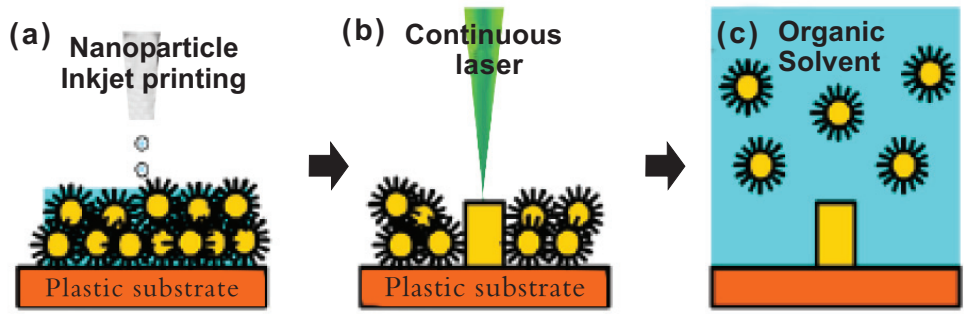

Fig. (2). Selective laser sintering of NPs inkjet printed on a polymeric substrate by scanning with a focused cv laser. The circles represent Au NPs within a self-assembled monolayer, and the column indicate a conducting site of a sintered pattern. Unsintered NPs can be simply washed out by a proper solvent. (Reproduced with permission from Ko SH, Pan H, Grigoropoulos CP, Luscombe CK, Fréchet JMJ, Poulikakos D. Nanotechnology 2007; 18:345202, IOP Publishing Ltd).

Microwave sintering of MC has not yet been reported.

\subsubsection{Plasma Sintering}

This type of sintering is applicable to both metal NPs and MC. It is performed by exposure of printed patterns to low pressure Ar plasma [37] and electron-cyclotron resonance (ECR) plasma [38].

\subsubsection{Electrical Sintering}

In this method, the sintering is reached by applying a voltage over the printed structure that causes current flow through the structure, leading to a local heating by energy dissipation [39]. The main advantages of this method are the short sintering time (from microseconds to tens of seconds) and reduced substrate heating. This method of sintering can be applied to MC inks, if combined with thermal treatment.

\subsubsection{Sintering by Chemical Agents at RT}

A new approach to achieve coalescence and sintering of metallic NPs at room temperature was recently reported [19, 40]. It was discovered that metal NPs undergo a spontaneous coalescence process when they come into contact with oppositely charged polyelectrolytes that enables achieving high conductivities even at room temperature. This makes possible the formation of conductive patterns on heat-sensitive plastic substrates and papers. It was found that when a positively charged polyelectrolyte, poly(diallyldimethylammonium chloride) (PDAC), is added to a dispersion of negatively charged Ag NPs, it causes a decrease in their zeta potential that results in triggering the coalescence of the nanoparticles at the point of zero charge. The same effect was observed for nanoparticles inkjet printed onto PET: a droplet of PDAC solution caused a spontaneous sintering of Ag NPs in the zone of the polycation droplet (Fig. 3). RT sintering was also demonstrated for printing onto substrates pre-coated with PDAC prior to printing.

\section{INKS BASED ON METAL NANOPARTICLES: PREPARATION AND PROCESSING}

Since practically all available conductive inkjet inks are based on $\mathrm{Ag}$ and $\mathrm{Cu}$ NPs and metallo-organic compounds, we will describe below several preparation methods and the properties of these inks.

\subsection{Preparation of Metal NPs}

Methods for metal NPs preparation to be used in conductive inkjet inks can be divided into two main strategies: topdown and bottom-up.
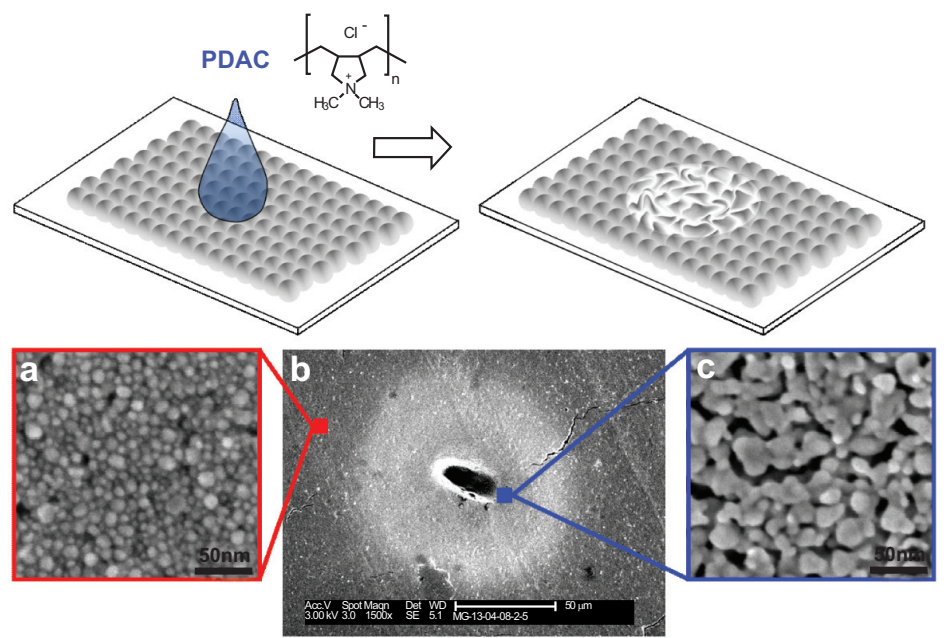

Fig. (3). Schematic illustration showing what happens when a droplet of PDAC solution is printed on a silver NPs array, and SEM images of the printed drop zone (b). Images (a) and (c) show the magnified NPs arrays after the contact with PDAC outside and inside the droplet zone, respectively. (Reproduced with permission from Magdassi S, Grouchko M, Berezin O, Kamyshny A. ACS Nano 2010; 4:1943-1948, American Chemical Society). 
Top-down, or physical methods are usually high-energy methods, in which bulk metal, or microscopic particles are converted to nanosized particles. Among the top-down methods, the most widely used are physical gas-phase methods based on the rapid condensation of metal vapor usually obtained by thermal heating or plasma excitation of metal plates, powders or wires followed by its transport with a stream of an inert gas $\left(\mathrm{N}_{2}, \mathrm{Ar}, \mathrm{He}\right)$ onto a solid substrate or into a liquid containing a stabilizing agent in order to accumulate, stock, and handle the metal particles [41, 42]. Among metal NPs prepared by the gas-phase method are Ag NPs in the size range of 4-10 nm [42-44], and Cu NPs [42, 45]. Another approach, laser ablation, also enables dispersing the bulk metal in either organic or aqueous medium [46]. This technique was employed for preparation of $\mathrm{Ag}$ and $\mathrm{Cu}$ NPs in the size range from 4 to $80 \mathrm{~nm}[23,47,48]$. The main disadvantages of gas-phase and laser ablation methods are the difficulties in obtaining uniform and stable NPs. In addition, these methods are expensive, energy-consuming, and require sophisticated equipment.

In bottom-up methods, NPs are built up from metal atoms and nuclei, which are formed either from precursor ions and molecules with the use of a proper reducing agent, or from precursor molecules by their decomposition [49-56]. Bottom-up preparation of metal NPs is usually performed in a liquid medium, which can vary from water to polar and nonpolar organic solvents and ionic liquids [53-58]. These approaches enable preparation of dispersions with various particle characteristics such as size and its distribution, morphology, and stability, by varying experimental parameters, such as the type and concentration of reagents and their redox potentials, temperature, $\mathrm{pH}$, rate of reagents addition, addition of seeds, and stabilizers [50-52, 59-65].

For the synthesis of $\mathrm{Ag}\left(E^{0}=0.8 \mathrm{~V}\right)$ and $\mathrm{Cu}\left(E^{0}=0.34\right.$ V) NPs in aqueous medium, borohydride, hydrazine, ascorbic acid, and citrate are usually used as reducing agents [59, 62-64, 66, 67].

As to the formation of Ag NPs in organic solvents, ethanol [68] and $N, N$-dimethylformamide [52, 69] can also function as reducing agents, but in most cases, formation of $\mathrm{Ag}$ and $\mathrm{Cu}$ NPs in organic solvents requires the addition of a dedicated reducing agent [26, 70-75].

The polyol method, in which the liquid polyol (ethylene glycol, propylene glycol, diethylene glycol) acts both, as the solvent of the metal precursor and as the reducing agent, is also a very suitable route to provide finely dispersed metals [55, 76-78].

A further mean for the formation of metal NPs in solution is the use of high energy irradiation (UV-, $\gamma$ - and electron beam) [79-83].

Aqueous dispersions of $\mathrm{Ag}$ and $\mathrm{Cu}$ NPs can also be obtained by electrolysis of a metal salt in solution [84-88] and by sonochemical [89-91], and sonoelectrochemical [92-95] methods.

Fatty-acid coated Ag NPs with an average size of $5 \mathrm{~nm}$, redispersible in hydrocarbons were obtained by thermal decomposition of complexes of silver with fatty acid [96, 97]. $\mathrm{Cu}$ NPs with a diameter of $7 \mathrm{~nm}$ were obtained by pyrolysis of dialkylamino alkoxide $\left[\mathrm{Cu}\left(\mathrm{OCH}(\mathrm{Me}) \mathrm{CH}_{2} \mathrm{NMe}_{2}\right)_{2}\right]$ in hot coordinating solvents (hexadecylamine, tri- $n$-octylphosphine oxide) [98], and NPs with diameters in the size range of 12$26 \mathrm{~nm}$ were obtained by thermal decomposition of $\mathrm{Cu}$-oleate complexes [99].

\subsection{Stabilization of Metal NPs Against Aggregation}

NPs in colloidal dispersions approach each other and collide due to Brownian motion, and this may result in their aggregation followed by irreversible coagulation and sedimentation, since the density of metal is very high compared to the density of typical liquids. The best approach to avoid this problem is to prevent aggregation of metal NPs at the early stages of their formation, while synthesizing the metal ink precursor. The selection of stabilizer, liquid vehicle, and stabilization procedure are of great importance, affecting ink shelf life and performance.

Stabilization of metal NPs against aggregation is achieved by two main mechanisms: electrostatic and steric. Electrostatic stabilization is a result of electrostatic repulsion between electrical double layers surrounding interacting particles. The crucial condition for obtaining stable dispersions is the value of the electric potential of the NPs: the higher it is the larger the electrostatic repulsion and the more stable the colloidal system. As a measure of the electrical potential of a particle, the zeta potential $(\zeta)$ is usually used. Dispersions of colloidal particles in water are considered stable at $|\zeta|>35-40 \mathrm{mV}$ (at $1: 1$ electrolyte concentration of $<10^{-2}$ mol $\left.\mathrm{dm}^{-3}\right)$. The disadvantage of electrostatic stabilization is its sensitivity to electrolyte concentration, which strongly affects the thickness of the electrical double layer, and obtaining stable dispersions of metallic NPs in polar media at high ion concentrations is difficult. In addition, the electrostatic mechanism is not effective in organic vehicles, and that requires an additional or different stabilization mechanism.

To overcome the problem, steric stabilization is frequently used as an alternative. Steric stabilization is achieved by surrounding the particle with an adsorbed layer of sterically bulky molecules, such as polymers, mostly nonionic.

In the case of charged polyelectrolytes, both electrostatic and steric stabilizations are simultaneously involved resulting in combined electrosteric stabilization of colloidal particles. The electrosteric mechanism is especially effective when stabilizing metal NPs in aqueous dispersions.

Very effective stabilizers of highly loaded dispersions of metal NPs, which can be used for inkjet ink formulations, are non-ionic amphiphilic polymers containing both hydrophobic and hydrophilic components. Their molecules are capable of binding to the surface of metallic NPs thus providing effective steric stabilization. The most frequently used is poly( $N$-vinyl-2-pyrrolidone) (PVP) of various molecular weights, which exhibits a highly effective protective function in both organic and aqueous media. PVP has been shown to be an effective stabilizer of aqueous dispersions of $\mathrm{Ag}$ and $\mathrm{Cu}$ NPs $[67,79,93-95,100-108]$ as well as an effective stabilizer of $\mathrm{Ag}$ and $\mathrm{Cu}$ NPs in organic solvents [69, 101, 109] and especially in polyol synthesis $[61,77,78,110]$. The polyol method, while using PVP as a stabilizer, was utilized in the preparation of $\mathrm{Ag}$ and $\mathrm{Cu}$ NPs (size range of 40-50 $\mathrm{nm})$ as precursors of metal-based conductive inks [111-115]. 
Polyelectrolytes combining both electrostatic and steric stabilization effects are, in general, very effective stabilizers. Examples of stabilizers for Ag NPs are: carboxymethyl cellulose sodium salt $[79,116]$; commercial dispersants such as polynaphthalene sulfonate formaldehyde condensate; Daxad 19 [64, 117]; Disperbyk 190 of BYK-Chemie, which is a high molecular weight block copolymer with acidic affinic groups [118]; and poly(acrylic acid) salts [8, 119-121].

\subsection{Stabilization of Metal NPs Against Oxidation}

Another problem arises while synthesizing and using NPs of easily oxidizable metals such as $\mathrm{Cu}$ and $\mathrm{Al}$. Even a very thin surface oxide layer can significantly affect the physical and chemical properties of the NPs. Therefore, synthesis of metal precursors and conductive ink formulations require optimal protection of NPs not only against aggregation but against oxidation as well.

It has been shown that stabilizing agents, which protect $\mathrm{Cu}$ NPs against aggregation, can also protect them against oxidation by markedly decreasing the oxidation rate. For example, copper oxides were not detected in dispersions of $\mathrm{Cu}$ NPs synthesized in water by reduction with hydrazine and stabilized by a CTAB bilayer [25]. PVP as a protective agent has also been shown to slow down the oxidation of $\mathrm{Cu}$ NPs due to the formation of a dense protective polymeric shell $[122,123]$. It was found that the higher the molecular weight of the polymer, the more effective its protective action [122]. Addition of antioxidants, such as ascorbic acid, was shown to sufficiently retard the rate of $\mathrm{Cu}$ NPs oxidation [108]. Alkanethiols and oleic acid were also found to improve stability of $\mathrm{Cu}$ NPs in air [124]. Deposition of a graphene layer also enables effective protection of a copper core up to $200^{\circ} \mathrm{C}$ in humid air [125].

Since protection of metal NPs by organic coatings only retards, but does not prevent their oxidation, an effective approach for obtaining non-oxidizable NPs as ink precursors is based on the formation of a protective shell made of a noble metal. Preparation of $\mathrm{Cu}$ core/Ag shell ( $\mathrm{Cu} @ \mathrm{Ag})$ NPs (Ag shell thickness of 1-50 nm) stable to oxidation was performed by addition of $\mathrm{Ag}$ dodecanoate to a dispersion of preformed $\mathrm{Cu}$ nanoparticles $(50-100 \mathrm{~nm})$ in organic solvents [75]. Magdassi et al. synthesized Cu NPs (40-50 nm) surrounded by a thin $\mathrm{Ag}$ shell (2-4 $\mathrm{nm}$ ) by transmetalation reaction, i.e. by direct reduction of $\mathrm{Ag}^{+}$ions by the surface $\mathrm{Cu}$ atoms $\left(\Delta E^{0}\right.$ $=0.46 \mathrm{~V})$ according to the scheme in Fig. $(4)[19,24]$.

The obtained composite NPs were found to be stable to oxidation in air: core/shell NPs retain their initial characteristics for at least two years, while unprotected NPs easily undergo spontaneous oxidation while exposed to air.

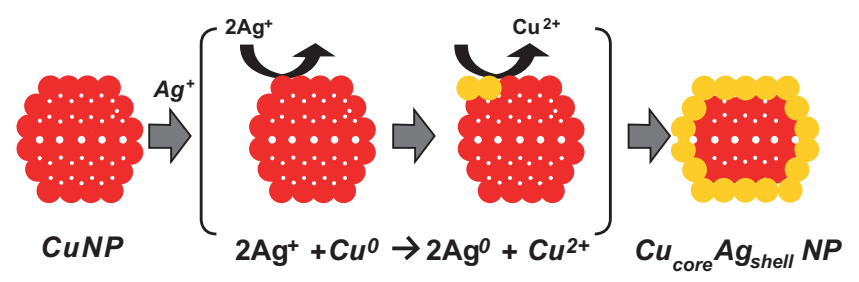

Fig. (4). Schematic illustration of $\mathrm{Cu} @ \mathrm{Ag}$ NPs formation by transmetalation reaction. (Reproduced with permission from Grouchko M, Kamyshny A, Magdassi S. J Mater Chem 2009; 19:3057-3062, The Royal Society of Chemistry).

\subsection{Ink Formulations}

\subsubsection{Metal NPs Applicable to Inkjet Ink Formulations}

Optimization of the metal precursor (type of metal, dispersing medium, stabilizing agent) is one of the crucial points in obtaining inks for printing patterns with high electric conductivity. Metal precursors can be either in the form of dispersions of metal NPs in water, organic solvent, and water/solvent mixture, or in the form of a nanopowder.

In general, even in the presence of stabilizers, the majority of the wet chemical procedures described so far yield stable dispersions of metallic NPs only at low concentrations of metal, in the range of $10^{-4}-10^{-2} \mathrm{~mol} / 1[53,119,121,126$ $135]$ and, therefore, are not suitable for large-scale manufacture of conductive inks, which require high metal loadings (usually 20-80\%) [1]. There are only a few reports on the direct preparation of concentrated dispersions of metal NPs. Dispersions of Ag NPs with sizes in the range of 10-30 nm and metal concentration of about $20 \%$ were prepared by reduction of $\mathrm{Ag}_{2} \mathrm{O}$ with gum arabic, which is also a stabilizing agent [136]. Dodecanoic acid-protected Ag NPs $(\sim 7 \mathrm{~nm})$ with a concentration of about $21 \%$ were synthesized in toluene [70]. Even more concentrated aqueous dispersions of $\mathrm{Ag}$ NPs (up to $40 \%$ ) with particle sizes of less than $10 \mathrm{~nm}$ were fabricated with the use of ammonium salt of poly(acrylic acid) with molecular weight of 15,000 as a stabilizing polyelectrolyte [8]. However, the directly synthesized concentrated dispersions of metal NPs contain usually high concentration of stabilizing polymers, which are insulators, and therefore are not applicable as inks for conductive printing with low temperature processing.

The conventional method for increasing the metal load in dispersions is separation of NPs by centrifugation [111-113, $115,118,122]$ or by precipitation with alcohols (methanol, ethanol, isopropanol) or acetone followed by washing the sediment with a proper solvent to remove the excess of stabilizing material $[25,59,100,111-113,115,117,118,122$, $128,137,138]$. The obtained nanopowders were successfully formulated into Ag-based [71, 104, 105, 112, 118, 139-145], Cu-based [111, 113, 122, 123, 146], and Cu@Ag-based [75] conductive inkjet inks. Redispersible silver nanopowder as a conductive ink precursor can also be obtained by lyophilization of low concentration dispersion [118, 146]. Metal nanopowder precursors prepared by gas-phase [42], laser ablation [23, 47, 48], and mechanochemical [147, 148] methods can also be used for conductive ink formulation. For example, Ag NPs prepared from strips of Ag/Al alloy by leaching of $\mathrm{Al}$ with the use of concentrated $\mathrm{NaOH}$ solution followed by treatment in an ultrasonic bath [149, 150] were used as precursors for solvent-based and water-based conductive inks [151].

\subsubsection{Ink Formulations and Printing Conductive Pattern}

Typical solvents for Ag-based inkjet inks described so far are water [118, 152, commercial Metalon JS-011 and JS-015 inks of Novacentrix]; alcohols and other oxygenated solvents $[12,13,144,153$, commercial Ag 50P ink of Samsung ElectroMechanics, IJ 242-54 ink of Cima NanoTech, and CKR ink of Sumimoto Metal Mining]; hydrocarbons, such as toluene $[13,141]$, tetradecane [154, commercial ink NPS-J of 
Harima, and $\mathrm{Ag} 60 \mathrm{~N}$ of Samsung ElectroMechanics]; and cyclohexane (commercial inks of NanoMas). However, the most often used vehicles are mixtures of various solvents such as water/alcohols [155], water/glycols [105, 146, 155, 156], and multicomponent mixtures containing water, oxygenated organic solvents, and glycerol [112, 143, 146, 155, 157]. Solvents for Cu-based and Cu@Ag-based inks described so far are mainly water [19, 24, 125], mixtures of oxygenated organic solvents $[17,35,75,111,113,122,123$, 145], and their mixture with water [158]. Cu NPs-based inkjet inks produced by Samsung ElectroMechanics contain diethylene glycol monobutyl ether $(\mathrm{Cu} 40 \mathrm{P})$ or tetradecane $(\mathrm{Cu} 40 \mathrm{~N})$ as solvents.

The most often used stabilizer for metal-based inks is the nonionic polymer PVP $[105,111-113,115,122,123,143-$ $145,155,157,158]$. Polyelectrolytes, such as sodium polyacrylate [19, 24], Solsperse 40 (anionic phosphated alkoxylated polymer) [146], Sokalan HP80 (polycarboxylate ether) [146], and Dysperbyk 190 (block copolymer with acidic affinity groups) $[118,125]$ were also used for ink stabilization. In some cases metal-based ink formulations contain various additives, such as dispersants [158], wetting agents [19, 24, $118,125,146]$, and adhesion promoters [158].

Typical morphologies of patterns printed with the use of $\mathrm{Ag}$ inks and sintered at different temperatures are shown in Fig. (5) [118]. Already at $150^{\circ} \mathrm{C}$, the particle size increases, and interconnections (necking) between NPs appear. At 200 ${ }^{\circ} \mathrm{C}$ and higher, dramatic changes in morphology are observed: most boundaries between particles disappear, and the sintering is obvious.

In some cases thermal sintering at temperatures as low as $150{ }^{\circ} \mathrm{C}$ produces printed patterns with rather low resistivities, only about 2 to 4 times greater than the resistivity of bulk metal $[12,13]$. Perelaer et al. [156] demonstrated that a sil-

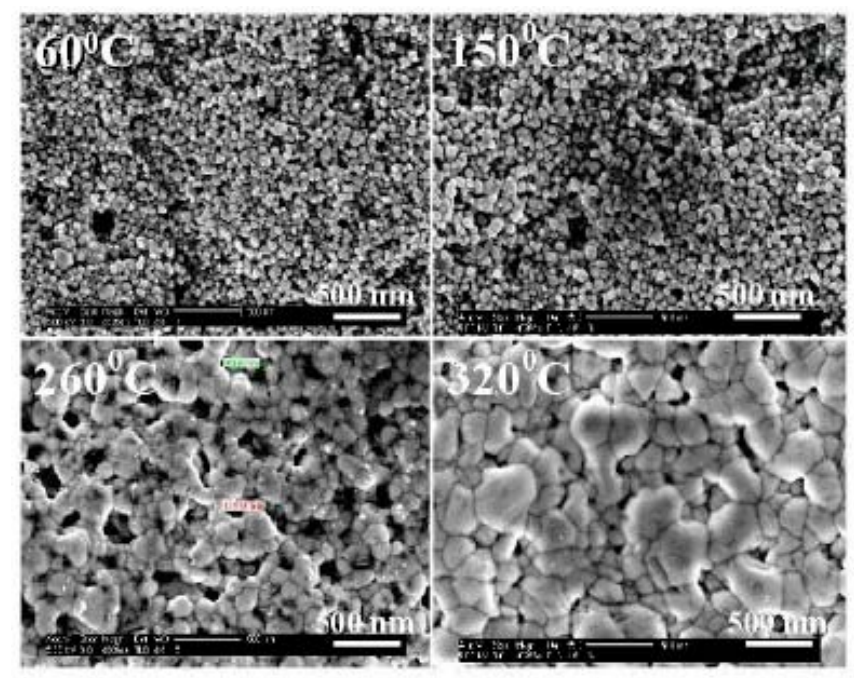

Fig. (5). SEM micrographs of the coating obtained by deposition of aqueous dispersion of Ag NPs $(8 \%$ metal, particle size $<50 \mathrm{~nm}$, stabilizer Disperbyk 190, wetting agent BYK 348) on a glass slide followed by sintering at different temperatures for $10 \mathrm{~min}$. (Reproduced with permission from Kamyshny A, Ben-Moshe M, Aviezer S, Magdassi S. Macromol Rapid Commun 2005; 26:281-288, Wiley-VCH Verlag GmbH\&Co. KGaA). ver ink containing a very low amount of organic additives revealed measurable conductivity already after curing at 80 ${ }^{\circ} \mathrm{C}$. Stepwise sintering $\left(80^{\circ} \mathrm{C}\right.$ for $5 \mathrm{~min}, 110^{\circ} \mathrm{C}$ for $5 \mathrm{~min}$, and $130{ }^{\circ} \mathrm{C}$ for $30 \mathrm{~min}$ ) of pattern printed onto photo paper with $\mathrm{Cu}$ ink $(10 \% \mathrm{Cu}$ in 1,2-dichlorobenzene) resulted in conductivities about $0.4 \%$ of that for bulk metal [159].

However, low resistivities (1.1-3 times of that for bulk metal) are usually reached only after sintering the printed patterns at temperatures above $200-250{ }^{\circ} \mathrm{C}$, sometimes as high as $400^{\circ} \mathrm{C}[70,111,112,144,154,155,157]$.

As to commercial metal NP inks, Novacentrix waterbased Metalon JS-011 (10\% Ag, particle size 200-400 nm) and Metalon JS-015 (15\% Ag, particle size 200-400 nm) as well as cyclohexane-based NanoSilver ink of NanoMas (10$30 \% \mathrm{Ag}$, particle size $2-10 \mathrm{~nm}$ ) are characterized by low sintering temperature $\left(100-150{ }^{\circ} \mathrm{C}\right)$ providing a resistivity 1.5-10 times of that for bulk Ag.

Photonic sintering with the use of high intensity light pulses (Novacentrix PulseForge technique) resulted in resistivities about 4 and 10 times of that for bulk $\mathrm{Ag}$ and $\mathrm{Cu}$, and the morphology of the sintered pattern was very similar to that at thermal sintering [160]. Sintering of $\mathrm{Cu}$ inks printed onto polyimide (PI) film $(10-17 \% \mathrm{Cu}$, particles size $<100$ $\mathrm{nm}$ ) with the use of a high-power pulsed Xe lamp resulted in resistivities 2.8, 4.6 and 11.6 times of that for bulk $\mathrm{Cu}$ depending on the ink vehicle (water/isopropanol, cyclohexanol/water/isopropanol, and isobutanol/water/isopropanol, respectively) [158].

After microwave sintering of a Harima ink $(\sim 60 \% \mathrm{Ag}$ in tetradecane (printed onto PI, and Cabot ink $(20 \% \mathrm{Ag}$ in ethylene glycol/ethanol) printed onto PEN (polyethylene naphthalate), the resistivities were found to be about 20 and 3 times of that for bulk Ag, respectively $[18,36]$.

Exposure of the pattern printed onto glass with the use of a Harima ink $(\sim 60 \% \mathrm{Ag}$ in tetradecane, particle size in the range of 5-10 nm) to low pressure Ar plasma resulted in a resistivity value 2.5-3 times that of bulk Ag [37].

Electrical sintering of tracks printed on photo paper with the use of Advanced Nano Products ink (34.5\% Ag with particle size in the range of $10-20 \mathrm{~nm}$ in triethylene glycol monoethyl ether) by applying a constant voltage resulted in resistivity of about 1.7 times of that for bulk Ag. A power density of at least $100 \mathrm{nW} \mu^{-3}$ was required to initiate the sintering process [39].

Room temperature chemical sintering of $\mathrm{Ag}$ inks $(30 \%$ Ag, average particle size $\sim 10 \mathrm{~nm}$ ) printed onto substrates that were pre-coated with a polyelectrolyte, PDAC, prior to printing, resulted in resistivities of metal tracks on copier paper and Epson photo paper of $70 \mu \Omega \cdot \mathrm{cm}$ and $6.8 \mu \Omega \cdot \mathrm{cm}$, 44 and 4.2 times greater that the resistivity of bulk Ag, respectively [40]. Similar sintering performance was observed for $\mathrm{Cu} @ \mathrm{Ag}$ NPs $(20-50 \mathrm{~nm})$ stabilized by polyacrylate and printed onto Epson photo paper pre-treated with 8\% phosphoric acid. The presence of phosphoric acid on the substrate surface leads to protonation of carboxylic groups of the stabilizer followed by spontaneous aggregation and sintering resulting in a printed pattern with resistance of $3 \Omega^{\cdot}{ }^{-1}$ [19]. 


\section{INKS BASED ON METAL COMPLEXES, SALTS AND ORGANO-METALLIC PRECURSORS: PREPA- RATION AND PROCESSING}

\subsection{Metal Complexes Applicable to Inkjet Ink Formula- tions}

MCs can be regarded as the ultimate approach to generating metal atoms via a chemical transformation that can occur in the gas phase, in solution or in the solid state. MCs are widely used in the production of thin metallic films in the semiconductor industry employing the process of chemical vapour deposition (CVD). As metal organic compounds present the largest class of reactive molecules used in this context, one commonly refers to the process as metal organic chemical vapour deposition (MOCVD). Conventional physical vapour deposition techniques (PVD) such as sputtering and evaporation are inadequate in providing sufficient step coverage as well as resulting in incomplete filling of high aspect ratio via holes or contacts. MOCVD (and CVD more generally) provides the advantage of chemical reactivity and selectivity, which enables the filling of more complex and demanding semiconductor topologies; this typically occurs at a much lower temperature. A further benefit arising from the chemical transformation of a MC into metal itself is that the process can also be carried out in solution or the solid state, though both are far less common than the gas phase route for reasons of scarcity of suitable MC precursors. More recently MOCVD has come even more into its own as a single molecule metal deposition route in the context of atomic layer deposition (ALD), where it is possible to deposit metallic mono- and multilayers in an iterative process [161, 162].

Common features in MC design are the combination of an anionic ligand balancing the charge of the metal ion in conjunction with a second (or third) donor or coordinating ligand (Fig. 6).

As coordinating and anionic ligands can be mono-, bi-, and multi-dentate, a variety of possibilities arise to define the environment around the metal atom. Ligands can be passive in the sense that they stabilize the metal cation but do not play any further roles. Active ligands are those, which, as part of the precursor complex reactivity, can undergo chemical transformation during the decomposition (e.g., alkoxides, which oxidize while the metal is being reduced at the same time). Anionic and coordinating ligands have to be selected carefully as they have to impart a number of properties onto the complex, some of which place opposing demands on the ligand structure. On the one hand, the MC should be stable (thermally, oxidatively and possibly photochemically) at room

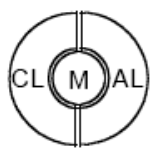

A

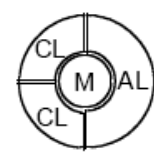

B

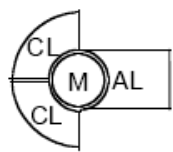

C

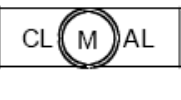

D
Fig. (6). Schematic illustration of MC precursor ligand arrangements. $\mathrm{AL}$ - anionic ligand; CL - coordinating ligand; $\mathrm{M}$ - metal cation.

temperature, while on the other hand the precursor ought to decompose cleanly into metal and byproducts at elevated temperatures. The level of impurities during the deposition step should be as low as possible, while at the same time the formation of metal layers should be fast and ideally substrate selective. For MOCVD in particular, it is desirable that the volatility of the complex is as high as possible.

The synthesis of $\mathrm{Cu}(\mathrm{I})$ and $\operatorname{Ag}(\mathrm{I})$ metal organic complexes is commonly achieved by reacting a transition metal salt with the desired oxidation state with a combination of an anionic ligand and a $\pi$-donor ligand in a one-pot reaction followed by purification [163-178]. Similarly, $\mathrm{Cu}(\mathrm{II}) \mathrm{MC}$ precursors are obtained in an analogous manner from $\mathrm{Cu}$ (II) salts [179-182]. In this section, we will present only a small number of examples illustrating more recent developments in the synthesis of MCs that can be used as components for metal inks.

Becker et al. reported low cost $\mathrm{Cu}$ (II) MOCVD precursors around an aminopropoxide ligand motif resulting in pure $\mathrm{Cu}$ films with a minimum resistivity of $2.2 \mu \Omega \cdot \mathrm{cm}$ when deposited at $260^{\circ} \mathrm{C}$ (Fig. 7) [179]. Addition of $\mathrm{H}_{2}$ into the carrier gas lowers the film forming temperature to around $170^{\circ} \mathrm{C}$.

Progress in developing $\mathrm{Cu}$ precursors for atomic layer deposition has been made by introducing new stabilizing ligands, a good example being amidinates as shown by Li et al. (Fig. 8) [162, 183]. Cu(I) N,N'-di-sec-butylacetamidinate vaporizes between $90-120{ }^{\circ} \mathrm{C}$ but already melts at $77{ }^{\circ} \mathrm{C}$. Hydrogen gas is required as a reductant and conducting substrate surfaces produce more homogeneous films, resulting in $\mathrm{Cu}$ films with resistivity of $2.9 \mu \Omega \cdot \mathrm{cm}$ for $80 \mathrm{~nm}$ thick film, that is $20 \%$ higher compared to $\mathrm{Cu}$ films obtained by PVD [161].

The related $\mathrm{Cu}(\mathrm{I})$ guanidinate complexes are also promising precursors for MOCVD with clean decomposition pathways starting at temperatures as low as $150^{\circ} \mathrm{C}$. Further developments are expected and could lead to improved precursor complexes with potential in ink formulations as part of a MOCLD process [184].

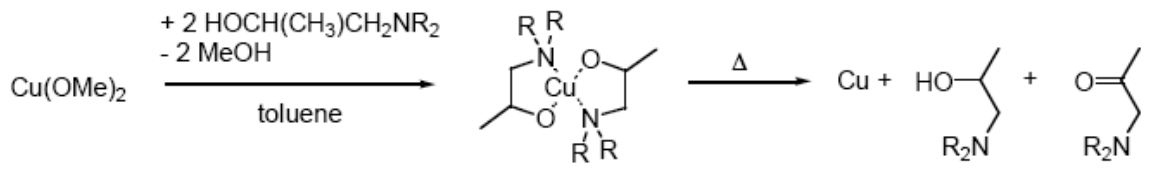

Fig. (7). Synthesis and decomposition chemistry of aminopropoxide stabilized self-reducing $\mathrm{Cu}(\mathrm{II}) \mathrm{MOCVD}$ precursors.
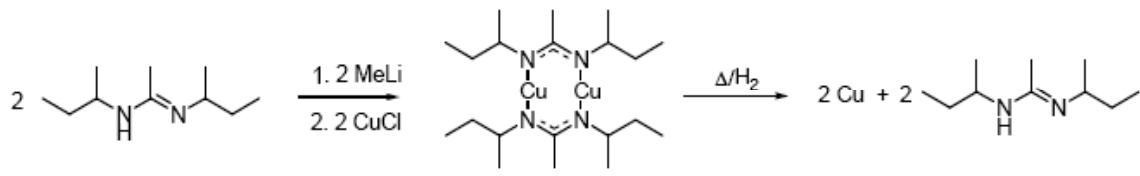

Fig. (8). Synthesis and decomposition chemistry of an amidinate $\mathrm{Cu}(\mathrm{I}) \mathrm{MOCVD}$ precursor. 
Desymmetrization of $\beta$-diketonate ligand structures imparts lower melting points and greater volatility on CVD $\mathrm{Cu}(\mathrm{I})$ precursors. Thermally induced disproportionation, as shown by Tran et al. [185], can be triggered at temperatures as low as $70^{\circ} \mathrm{C}$ with conversion completed at $120^{\circ} \mathrm{C}$ without having to resort to any fluorinated ligand features. The same effect on precursor properties has been observed for the nitrogen-analogous 1,3-diketimines [180].

\subsection{Deposition of Metal Complexes}

The majority of metal complexes for MOCVD exhibit surface-dependent deposition characteristics. The key surface characteristics responsible for this behavior are surface roughness, surface energy, and the chemical nature of the surface [186], which includes conductivity, as would be expected for surface deposition processes undergoing redox reactions. In order to facilitate and/or accelerate film growth, surface pre-treatment is usually required.

Additives can also lead to changes in growth rate and film purity. The addition of ethanol in the MOCVD of (hfac) $\operatorname{Ag}(\mathrm{COD})$ (hexafluoroacetylacetonato)silver(I)(1,5 cyclooctadiene) is one such example, where Bahlawane et al. [187] identified the surface dehydrogenation of ethanol as the mechanism responsible for faster precursor conversion. Under the same conditions, $\mathrm{AgNO}_{3}$ forms pure silver films at growth rates up to $18.5 \mathrm{~nm} \cdot \mathrm{min}^{-1}$ with resistivities of $<2$ $\mu \Omega \cdot \mathrm{cm}$ for $400 \mathrm{~nm}$ thick films grown at $573 \mathrm{~K}$. The same methodology was also extended to $\mathrm{Cu}$ precursors with similarly positive results of near bulk resistivity copper films [188, 189].

Usually the presence of oxygen is rather detrimental to CVD processes causing undesired oxidation byproducts. That this is not necessarily the case, was found by Lay et al. [190], while studying two new self-reducing partially fluorinated $\mathrm{Cu}$ (II) bis(iminoalkoxide) and bis(aminoalkoxide) complexes. $2-8 \%$ of $\mathrm{O}_{2}$ mixed into the Ar carrier gas led to the best results for resistivity and deposition kinetics in the range of $275-300^{\circ} \mathrm{C}$ possibly because oxygen aids the oxidation of ligand fragments during the decomposition process and thus reduces film contamination.

\subsection{Ink Formulations and Printing Conductive Patterns}

\subsubsection{Silver Inks}

Teng and Vest [191] performed an inkjet metallization of silicon SCs with the use of Ag neodecanoate in xylene. Repeated 4-5 layer deposition was necessary to minimize contact resistance of the silver films cured for $50 \mathrm{~min}$ with maximal temperature of $300{ }^{\circ} \mathrm{C}$.

Kodas et al. [192] have summarized claims for a wide range of inkjet inks suitable for printing low viscosity formulations. Several $\mathrm{Ag}$ and $\mathrm{Cu}$ inks for inkjet printing were specified, which allowed formation of metallic deposits on various substrates (PI, Si, glass) with conductivity close to bulk conductivities of corresponding metals after thermal treatment at $220-250^{\circ} \mathrm{C}$ for about $30 \mathrm{~min}$.

Dearden et al. [193] reported inkjet printing of solutions of Ag neodecanoate. Preparation of the ink involved the straightforward synthesis of the Ag salt followed by its dissolution in xylene. Ink viscosity for a $16 \% \mathrm{Ag}$ ink formula- tion was reported as $4.04 \mathrm{mPa} \cdot \mathrm{s}$ with a surface tension of 28 $\mathrm{mN} \cdot \mathrm{m}^{-1}$. Heating for $5 \mathrm{~min}$ at $150^{\circ} \mathrm{C}$ resulted in resistivities in the range of $3.0-4.8 \mu \Omega \cdot \mathrm{cm}, 2-3$ times of that for bulk silver.

Silver hybrid inks composed of dodecylamine-coated 5 $\mathrm{nm} \mathrm{Ag} \mathrm{NPs} \mathrm{and} \mathrm{a} \mathrm{coordination} \mathrm{complex} \mathrm{of} \mathrm{butylamine} \mathrm{and}$ $\mathrm{AgNO}_{3}$ in tetradecane [194] were deposited by jetting that resulted in $31 \mu \Omega \cdot \mathrm{cm}$ resistivity of $\mathrm{Ag}$ films after sintering at $150{ }^{\circ} \mathrm{C}$ for $30 \mathrm{~min}$.

Printing (hfac)AgCOD, dissolved in ethanol, on glass substrate followed by annealing at $300{ }^{\circ} \mathrm{C}$ for $20 \mathrm{~min}$ resulted in formation of a metallic layer with a resistivity of $\sim 5$ $\mu \Omega \cdot \mathrm{cm}$, which is a little over a factor of two higher than the resistivity of bulk Ag [14, 195-197].

Silver patterns inkjet printed on glass and PI with the use of commercially available organometallic ink (Gwent Electronic Materials Ltd.) and sintered at $150{ }^{\circ} \mathrm{C}$ in air for $1 \mathrm{~h}$ were characterized by the resistivity about 1.3-2 times of that of bulk silver $(2-3 \mu \Omega \cdot \mathrm{cm})$ [198].

Reinartz [199] jetted an aqueous solution of a silver salt, $\mathrm{AgNO}_{3}$, and aliphatic amine onto photo paper. At the next step, a reductive ink containing formaldehyde was deposited on wet printed pattern, and the paper was dried at $50{ }^{\circ} \mathrm{C}$ for $15 \mathrm{~min}$. This process was repeated twice and produced silver features with a resistivity less than $0.1 \Omega \cdot^{-1}$.

A new class of silver complexes was obtained by reacting silver oxide, $\mathrm{Ag}_{2} \mathrm{O}$, with ammonium carbamate or carbonate derivatives [200]. In the case of silver 2-ethylhexylammonium 2-ethylhexylcarbamate, its solution in isopropanol was patterned on a PET film with an inkjet printer. After heat treatment at $80{ }^{\circ} \mathrm{C}$ for $5 \mathrm{~min}$ and $130{ }^{\circ} \mathrm{C}$ for $10 \mathrm{~min}$, a metal pattern having a resistivity of $200-300 \mathrm{~m} \Omega \cdot^{-1}$, was obtained. Improved formulations with resistivity values as low as $20 \mathrm{~m} \Omega^{-1}$ have been claimed by the same group [153].

Gamerith et al. successfully jetted a commercial organosilver compound ink (Gwent Electronic Materials Ltd.) to produce source/drain metal electrodes for organic fieldeffect transistors (OFET) [13]. Sintering at $250{ }^{\circ} \mathrm{C}$ for $75 \mathrm{~min}$ resulted in a conductivity of $1.7 \cdot 10^{5} \mathrm{~S} \cdot \mathrm{cm}^{-1}$, about $27 \%$ of the conductivity of bulk silver.

Inkjet printing of $\mathrm{Ag}$ source/drain electrodes with $\mathrm{AgNO}_{3}$ inks as a low cost method for the fabrication of thin film organic transistors was reported by Xue and co-workers [201]. Inks were formulated in water/DMSO mixtures and jetted directly onto a $\mathrm{SiO}_{2}$ layer. Coating the silicon oxide surface with a thermally crosslinked poly(4-vinylphenol) dramatically changed the surface properties resulting in conducting silver films $(500 \mu \Omega \cdot \mathrm{cm})$ after annealing at $210{ }^{\circ} \mathrm{C}$ for $60 \mathrm{~min}$ in air.

Self-reducing silver inks composed of silver trifluoroacetate, ethylene glycol and Triton X-100 were formulated by Ginley et al. [202]. Resistivity of silver films after printing on substrates (glass, silicon) heated to $200-250{ }^{\circ} \mathrm{C}$ was found to be about $2 \mu \Omega \cdot \mathrm{cm}$, very close to that of bulk $\mathrm{Ag}$.

A solution composed of $25 \%$ water, $27 \%$ DMSO and $48 \% \mathrm{AgNO}_{3}$ by weight with a viscosity of $4.5 \mathrm{cP}$ and surface tension of $41 \mathrm{mN} / \mathrm{m}$ was printed on PET substrate [203]. Printing was followed by reduction of the film by hydrazine 
for $10 \mathrm{~min}$ at $120^{\circ} \mathrm{C}$. Produced silver films were characterized by a conductivity of about $10 \%$ of that of bulk silver.

Recently Perelaer et al. developed a one-step inkjet process to produce metal lines on glass and on plastic foils [204]. Silver salt ink with viscosity of $10 \mathrm{cP}$ was jetted directly onto the pre-heated substrate triggering solvent evaporation and sintering as a combined process. Heat treatment at 130 ${ }^{\circ} \mathrm{C}$ for $5 \mathrm{~min}$ resulted in conductivity values of 8 times of bulk silver. Increasing temperature and sintering time noticeably reduces this value. The same group developed a photochemical process, which can be carried out entirely at ambient temperature [205] with silver films of conductivities of $6.5 \cdot 10^{6} \Omega^{-1} \cdot \mathrm{m}^{-1}$.

Jakob et al. have recently claimed inkjet inks based on new, aqueous solutions of silver carboxylate precursors [206]. The silver content of the aqueous ink with a viscosity of $1.7 \mathrm{cP}$ was $9.1 \%$. Sintering of the dried ink for $30 \mathrm{~s}$ at 220 ${ }^{\circ} \mathrm{C}$ produced films with a conductivity of $1.9 \cdot 10^{6} \mathrm{~S}^{\cdot} \mathrm{cm}^{-1}$, which is about $3 \%$ of bulk silver. Photoirradiation at $135^{\circ} \mathrm{C}$ for $2 \mathrm{~h}$ produced $\mathrm{Ag}$ films with similar conductivity.

\subsubsection{Copper Inks}

An early incarnation of ink jetted copper precursors was investigated by Rozenberg et al. adapting $\mathrm{Cu}(\mathrm{I}) \mathrm{CVD}$ precursors as a liquid-phase CVD process (MOCVD) [207]. A solution of vinyltrimethylsilane $\mathrm{Cu}(\mathrm{I})$ hexafluoroacetylacetonate was inkjet printed directly onto a glass substrate at temperatures below $200{ }^{\circ} \mathrm{C}$. Copper-rich deposits were formed immediately on impact of the droplet on the heated surface. Porosity of the deposit was evident and caused by the volatile $\mathrm{Cu}\left((\mathrm{II})(\mathrm{hfac})_{2}\right.$ complex as a result of the disproportionation process of the MC precursor. A novel, multinuclear $\mathrm{Cu}$ precursor designed to have more favourable properties for low-temperature inkjet patterning processes was developed by the same group [208]. Tetravinylsilane tetrakis $\mathrm{Cu}(\mathrm{I})$ 1,1,1,5,5,5-hexafluoroacetylacetonate, (TVST) $\mathrm{Cu}$ (hfac), is a solid at room temperature and thus can be stored more easily than liquid copper complex precursors (Fig. 9). Upon addition of tetravinylsilane, a dynamic equilibrium produces lower nuclearity complexes, which are liquids and can be uids and can be inkjetted neat, thereby maximizing the available copper content of the ink [209].

Generally the volatility and high reactivity of these copper complexes resulted in a combination of vapour deposited and liquid deposited copper features forming a metal halo around the actual copper deposit (Fig. 10).

Rickerby et al. were able to show that the formation of such haloes can be minimized through the use of polymeric siloxane copper precursor inks (Fig. 11) also based on vinyl silane and hfac ligand systems [210]. Ink deposits were analyzed by particle induced X-ray emission (PIXE) and Rutherford backscattering spectrometry (RBS). Compared to a non-polymeric copper ink, haloing has been suppressed significantly, the thermal properties of the precursor as well as the conditions under which the ink is being deposited need to be optimized to achieve more regular and better defined features. Although polysiloxane are known to depolymerize at elevated temperatures more thermally labile polymer backbones need to be investigated (e.g. aliphatic polycarbonates) for improved deposition performance.

Self-reducing copper inks composed of $\mathrm{Cu}(\mathrm{II})$ formate tetrahydrate, $\mathrm{Cu}\left(\mathrm{HCO}_{2}\right)_{2} \cdot 4 \mathrm{H}_{2} \mathrm{O}$, ethanolamine and ethylene glycol were formulated by Ginley et al. [202]. Resistivity of copper films after printing on substrates (glass, silicon) heated to $200-250{ }^{\circ} \mathrm{C}$ was found to be about $10 \mu \Omega \cdot \mathrm{cm}$ that is one order of magnitude higher than for bulk $\mathrm{Cu}$.

Barrière et al. [211] performed reduction of a solution of copper mesitylene at room temperature by addition of (diisopropyl)amino borane acting as a very mild reducing agent. Dense $100 \mathrm{~nm}$ thick homogeneous copper films with a resistivity of $3.0 \mu \Omega \cdot \mathrm{cm}$ were obtained on silicon oxide substrates without post-sintering.

\subsubsection{Aluminum Inks}

Only very recently, Al inks, which can be used at atmospheric pressure as printable formulations and not as part of a modified CVD process, have been claimed. Curtis et al. [212] printed amine coordination complexes of alane, $\mathrm{H}_{3} \mathrm{AlNR}_{3}$, and trialkyl aluminum compounds $\left(\mathrm{R}_{3} \mathrm{Al}\right)$ on a
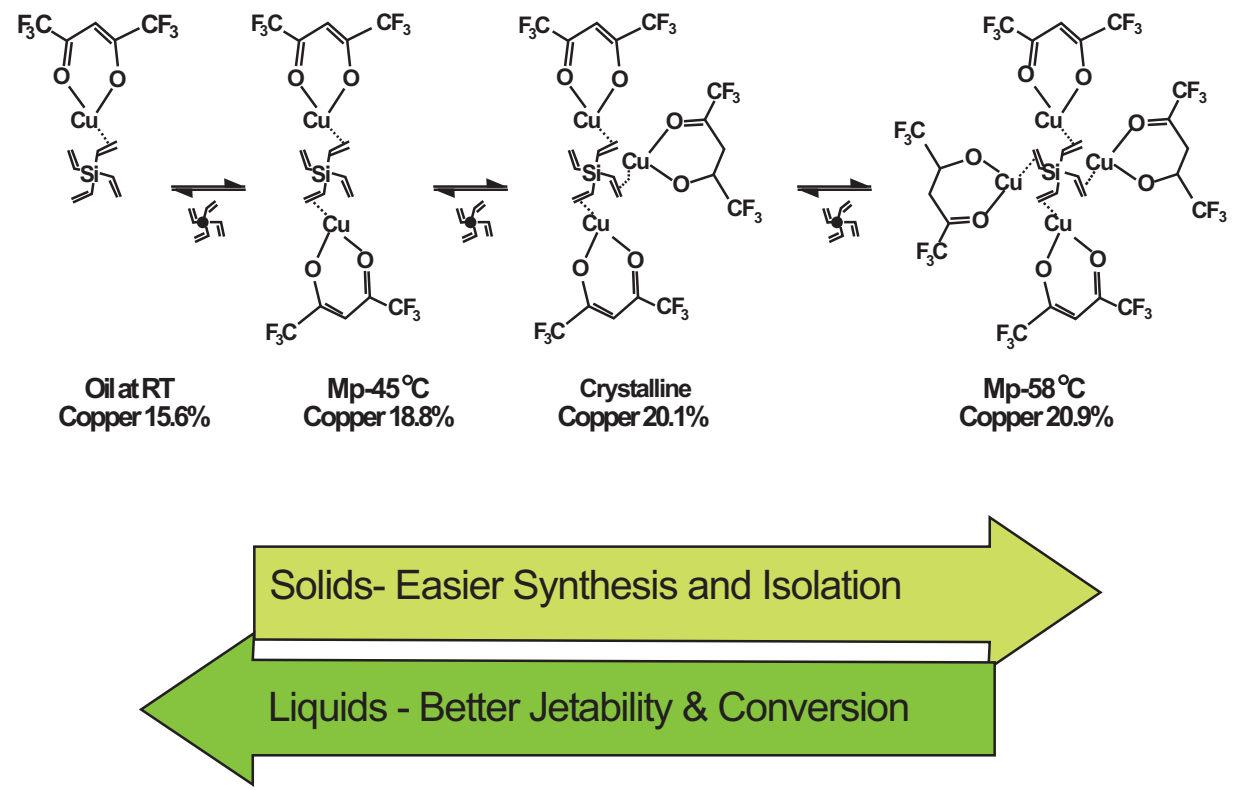

Fig. (9). The dynamic equilibrium of (TVST)Cu(hfac) driven by $\mathrm{Cu}(\mathrm{hfac})$ to tetravinylsilane stoichiometry. 


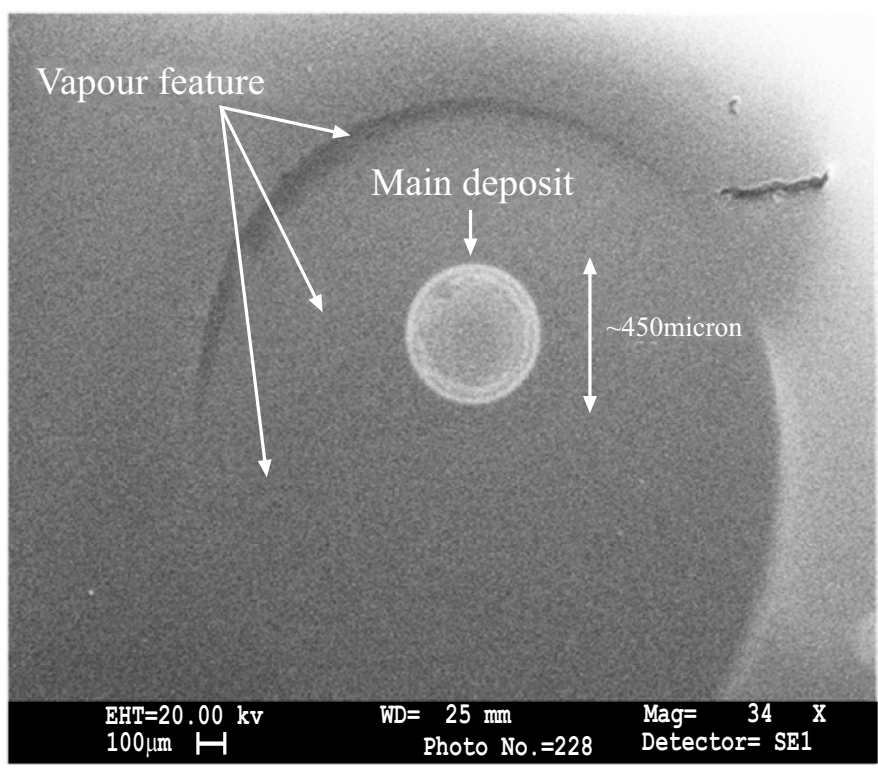

Fig. (10). SEM image of converted VTMS(Cu)hfac droplets on a glass substrate. The substrate was heated to $200{ }^{\circ} \mathrm{C}$. Each deposit feature originates from a single droplet. Please note the halo (vapor) features.
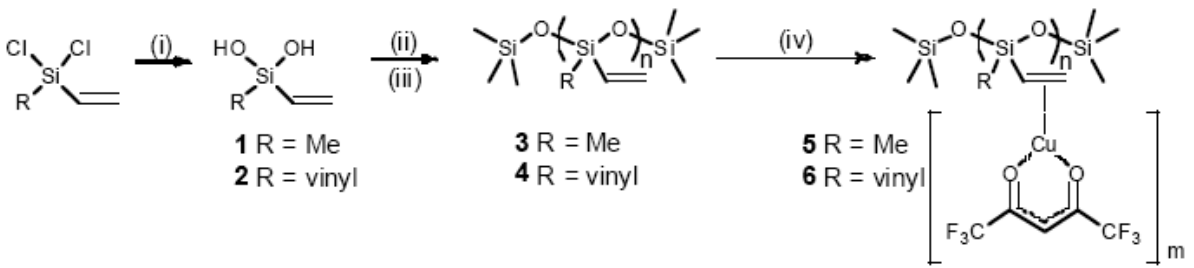

Fig. (11). Synthesis of a polymeric $\mathrm{Cu}(\mathrm{I})$ precursor aimed at reducing halo formation during inkjet printing on a heated substrate.

silicon substrate of a solar cell heated to temperature greater than about $140^{\circ} \mathrm{C}$, under inert $\mathrm{N}_{2}$ atmosphere.

Rockenberger et al. [213] refers to a broad range of aluminum compounds, stabilized with donor ligands and capable of decomposition at temperature around $100{ }^{\circ} \mathrm{C}$. The process is anticipating the expected use of printing and curing under inert conditions.

\section{APPLICATION OF METAL-BASED INKS}

\subsection{Solar Cells}

SCs are photovoltaic arrays containing a material that converts solar radiation into electrical current. Crystalline silicon SCs constitute more than $85 \%$ of the world photovoltaics market with a tendency to grow [214], while polycrys- talline and amorphous Si-based SCs are also used. Amorphous, or thin-layer SCs (thickness is less than $1 \mu \mathrm{m}$ ) prepared by deposition of Si film on glass or another proper material, are cheap, but have much lower efficiency compared with crystalline and polycrystalline SCs.

SCs are in fact large area semiconductor diodes (Fig. 12). At the p-n junction formed by diffusing n-type dopant (e.g., phosphorus) into the top surface of a p-doped wafer (e.g. boron as a dopant), an electric field is built up, that leads to the separation of the charge carriers (electrons and holes). If the circuit is close due to the presence of metallic contacts, then direct current flows. The SC also includes on the front surface a layer of antireflective material (antireflective coating, ARC), typically silicon nitride, $\operatorname{SiN}_{x}$, to increase the amount of absorbed light, and as a passivation layer, which

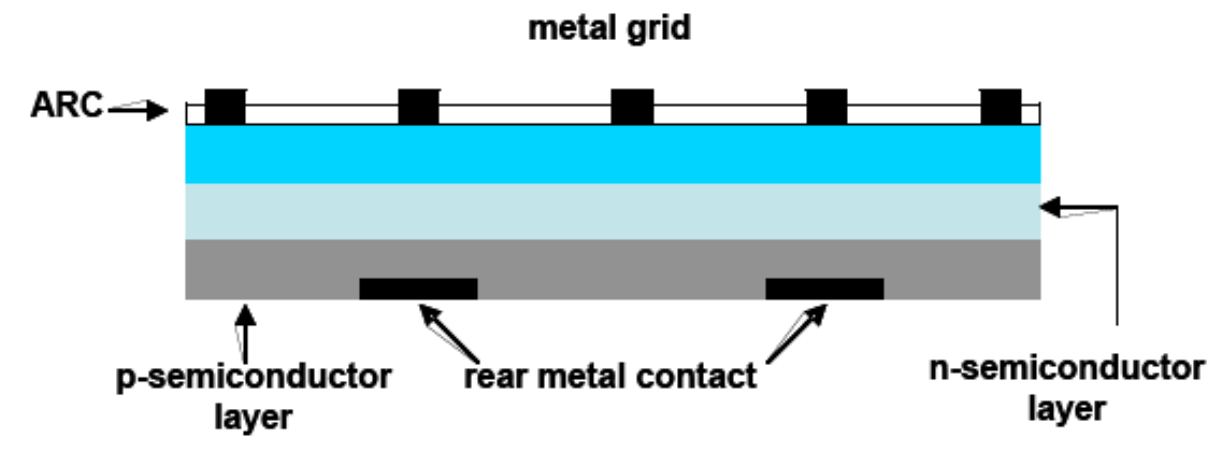

Fig. (12). Schematic presentation of a SC. 
passivates the bulk defects present in the wafer. The electrical contact layers on the illuminated side of the SC are usually present as a grid pattern, which does not cover the entire face of the cell, since the conductor layer is not transparent to light. Such a "collector" grid should possess high electric conductivity in order to avoid ohmic loss decreasing the efficiency of SC. Metals such as Ag and Al can be used for formation of the electrical contact layers.

The predominant technique for formation of electrical contacts is screen printing of a Ag-based thick-film paste and firing through the ARC layer providing very low sheet resistivity (down to $0.015 \Omega^{-1}$ for $40 \mu \mathrm{m}$ thick layer) [215217]. More than $85 \%$ of all silicon SCs are made with such thick film contacts [215].

Direct inkjet printing of the grid pattern offers a low-cost metallization technology alternative to screen-printing. Inkjet printing of grid patterns on single crystal silicon SC with the use of metallo-organic decomposition (MOD) ink (Ag neodecanoate in xylene) was reported for the first time by Teng and Vest in 1988 [191]. Repeated 4-5 layer deposition was necessary to minimize contact resistance of the silver films, which were fire in air using a $50 \mathrm{~min}$ cycle with a temperature profile of $\mathrm{T}_{\max }$ at $300^{\circ} \mathrm{C}$. The sheet resistance of the printed $\mathrm{Ag}$ layers was found to be similar to that for thinfilms-evaporated $\mathrm{Ag}\left(0.5-1.0 \Omega{ }^{\cdot-1}\right)$. The last stage of the process was thermal spiking at $800^{\circ} \mathrm{C}$ that resulted in easier $\mathrm{Ag}$ penetration into ARC thus providing better Si-metal contact.

Ginley et al. made valuable contribution to the application of inkjet printing for direct metallization of SCs [196, 202, 212, 218, 219]. Deposition of ink containing Ag NPs $(100-300 \mathrm{~nm})$ dispersed in toluene onto n-type silicon substrates followed by annealing at $882{ }^{\circ} \mathrm{C}$ for $1 \mathrm{~h}$ under Ar resulted in a current-voltage curve characteristic of good ohmic contact. Al NPs $(50-300 \mathrm{~nm})$ were etched with hexafluoroacetylacetone to remove the surface oxide layer and then deposited onto p-type silicon substrate. Treatment of the obtained Al layer as described above for $\mathrm{Ag}$ deposition, resulted also in linear current-voltage response [218]. In another example, highly conductive tracks (up to $15 \mu \mathrm{m}$ thickness) of $\mathrm{Ag}$ and $\mathrm{Cu}$ were inkjet printed onto silicon substrate heated to $200-250{ }^{\circ} \mathrm{C}$ with the use of self-reducing inks based on silver trifluoroacetate and copper formate. The obtained resistivities were as low as $2 \mu \Omega \cdot \mathrm{cm}$ and $10 \mu \Omega \cdot \mathrm{cm}$, respectively [202]. Formation of metal contact on silicon with ARC was also performed by inkjet printing a silver organo-metallic compound followed by high temperature annealing in order to alloy the metallic layer to the silicon through the burn-through-layer [219]. The aluminum contact layer was printed on silicon substrate heated to $150-200{ }^{\circ} \mathrm{C}$ in inert atmosphere $\left(\mathrm{Ar}\right.$ or $\mathrm{N}_{2}$ ) with the use of organometallic Al compound (amine complex or alane) [212].

The above examples clearly demonstrate the applicability of the inkjet printing in the fabrication of highly conductive metallic contacts on the surface of silicon SCs.

\subsection{Transistors}

Printed organic thin-film transistors (TFT) have received growing interest in recent years as a low-cost alternative to conventional silicon-based transistors [2, 220]. While using large-scale integration of several devices, high conductivity of the interconnections is essential. Formation of contacts by inkjet printing is a novel approach to form electrical contacts on such transistors [2, 221-223].

For example, Ag source/drain electrodes with top contact geometry were directly printed on pentacene film of organic TFT built on PI substrate [221] followed by sintering at temperatures of $130-140{ }^{\circ} \mathrm{C}$ for $1-2 \mathrm{hrs}$. Such sintering did not destroy the organic semiconductor layer, and the resistivity of the printed electrodes was found to be $<25 \mu \Omega \cdot \mathrm{cm}$, which is sufficiently low for practical applications [222, 223]. Printing with the use of mixed $\mathrm{Ag}-\mathrm{Cu}$ NPs dispersion in buthoxy(ethylacetate) (Cima NanoTech) and sintering at 150 ${ }^{\circ} \mathrm{C}$ for $45 \mathrm{~min}$ followed by $200{ }^{\circ} \mathrm{C}$ for $1 \mathrm{~h}$ resulted in conductivity of about $1.15 \%$ of that for bulk $\mathrm{Ag}$ [13].

Metal salts and metallo-organic compounds have also been used as inks for printing electrodes on organic TFT. Printing of $\mathrm{AgNO}_{3}$ dissolved in a mixture of water and dimethyl sulfoxide onto pre-deposited poly(3-vinylphenol) film followed by sintering at $200{ }^{\circ} \mathrm{C}$ for $1 \mathrm{~h}$ resulted in $\mathrm{Ag}$ tracks with a resistivity of $5 \cdot 10^{-4} \Omega \cdot \mathrm{cm}$ [201]. Printing of silver neodecanoate ( $25 \%$ in xylene) onto a film of organic electron acceptor 2,3,5,6-tetrafluoro-7,7,8,8-tetracyanoquinodimethane $\left(\mathrm{F}_{4} \mathrm{TCNQ}\right)$ followed by sintering at $160^{\circ} \mathrm{C}$ for $20 \mathrm{~min}$ resulted in a silver track resistivity of $2 \cdot 10^{-7} \Omega \cdot \mathrm{cm}$ [222]. Metal films obtained by printing a toluene-based organosilver ink of Gwent Electronic Materials onto poly(3hexylthiophene) led to conductivities of $1.7 \cdot 10^{5} \Omega^{-1} \cdot \mathrm{cm}^{-1}$ after curing at $250{ }^{\circ} \mathrm{C}$ for $75 \mathrm{~min}$ [13]. Copper hexanoate dissolved in isopropanol has been used as ink for printing metal electrodes onto silicon TFT. After curing at $200^{\circ} \mathrm{C}$ for 30 min in reducing atmosphere $\left(\mathrm{H}_{2}\right.$ gas in $\left.\mathrm{N}_{2}\right)$, the resistivity of electrodes was measured as $\sim 10 \mu \Omega \cdot \mathrm{cm}[224]$.

\subsection{OLEDs and Electroluminescent Devices}

The success over the past few years indicates that OLEDs are the ideal candidate for future lighting. Large area OLEDs and other electroluminescence (EL) devices require a highly conductive grid ("shunting lines") as a key component in order to ensure a homogeneous distribution of the current within the device and to prevent the voltage drops, which lead to a fading in light intensity. In addition, since the current needs to "enter" the lighting area, a highly conductive high current density circuit is required around the lighting device. Here inkjet printing technology paves the way for direct low-cost and environmentally friendly fabrication of these electric circuits on heat sensitive plastic substrates. A flexible, transparent EL device constructed in two steps is demonstrated in Fig. (13): (i) a four-layer (PET:ITO:ZnS: $\mathrm{BaTiO}_{3}$ ) EL device (MOBIChem Scientific Engineering, Israel) was coated by PDAC as a RT sintering agent on the top of the $\mathrm{BaTiO}_{3}$ layer and dried at room temperature; (ii) a silver dispersion was inkjet printed directly on the top of the PDAC layer. Voltage $(100 \mathrm{~V})$ applied between the ITO and $\mathrm{Ag}$ electrodes resulted in light emission $(90 \mathrm{~cd} / \mathrm{sqm})$ following to the $\mathrm{Ag}$ printed pattern [40].

\subsection{RFID}

RFID provides a means of storing and remotely reading data from any item equipped with an identification tag. The basic elements of an RFID tag are a microchip and an an- 


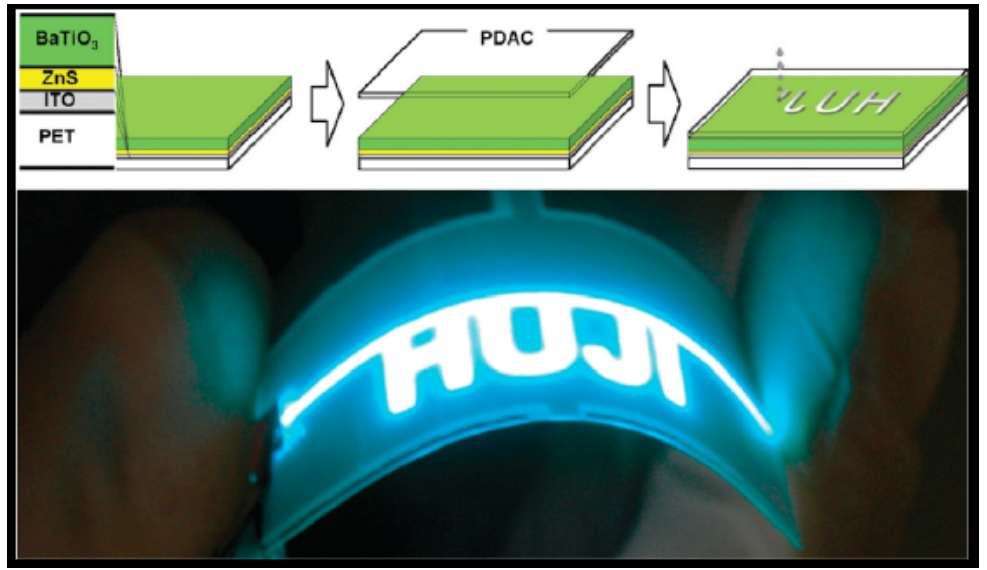

Fig. (13). Top: schematic illustration of the EL device and the printing process. Bottom: working EL device. (Reproduced with permission from Magdassi S, Grouchko M, Berezin O, Kamyshny A. ACS Nano 2010; 4:1943-1948, American Chemical Society).

tenna, the latter is typically fabricated by stamping/etching, silk screening or lithographic techniques. Direct printing of antennas on plastic substrates with the use of conductive inkjet inks generates sufficient simplification of the process and cost savings associated with it. Inkjet printing also enables the antenna to be easily attached to the microchip providing robust bonding.

Since the antenna should be of low resistivity (the read distance of RFID tags decreases with a decrease in the antenna conductivity), Ag- and $\mathrm{Cu}$-based inks are preferable [159]. An RFID antenna printed with the use of aqueous dispersion of $\mathrm{Cu} @ \mathrm{Ag}$ NPs onto inkjet paper is shown in Fig. (14) [24]. The resistance of the printed $\mathrm{Cu} / \mathrm{Ag}$ antenna was measured to be $3 \Omega \cdot{ }^{-1}$ [19].

One more example are RFID antennas inkjet printed onto PI film with the use of a Cabot ink $(20 \%$ dispersion of $\mathrm{Ag}$ NPs with an average diameter of $30 \mathrm{~nm}$ in ethanol/ethylene glycol mixture): coil antenna targeted for operation at 13.56 $\mathrm{MHz}$ and dipole-based UHF antenna targeted for the 867 $\mathrm{MHz}$ frequency. Sintering at $240{ }^{\circ} \mathrm{C}$ for $15 \mathrm{~min}$ resulted in wiring resistivity of $6.2-6.6 \mu \Omega \cdot \mathrm{cm}$, that is only about 4 times higher compared to bulk Ag [225].

\section{OUTLOOK}

Inkjet printing with the use of inks based on metal NPs and metallo-organic decomposition inks is considered to be an innovative technique for high quality and low cost metallization. Applied to printed electronics, inkjet printing enables direct high resolution metallic patterning on various substrates, including flexible heat sensitive polymers. Current high price of commercially available conductive inkjet inks and high sintering temperatures required for obtaining conductive printed patterns impede their use for printed large area plastic electronics. Therefore, $R \& D$ efforts should be focused on development of new inks based on low cost metals with high conductivity tailored for low temperature sintering to provide a simple, low cost, energy efficient, environmentally friendly and R2R compatible platform to produce highly conductive structures with high resolution.

Since obtaining conductive printed patterns on plastic substrates, in addition to inkjet formulations, requires also the low-temperature sintering, a detailed understanding of the metal nanoparticles sintering process as well as development of the emerging sintering techniques (photonic, microwave, plasma, chemically triggered room temperature coalescence) are crucial. The efforts here should be focused on optimization of the whole process ink formulationprocessing-sintering.

As to MC inks, they have shown the greatest advance over the last 5-10 years resulting in silver-based formulations that can be printed in air, at ambient temperatures and with annealing temperatures suitable for cheap plastic films while reducing the curing time to sometimes seconds.
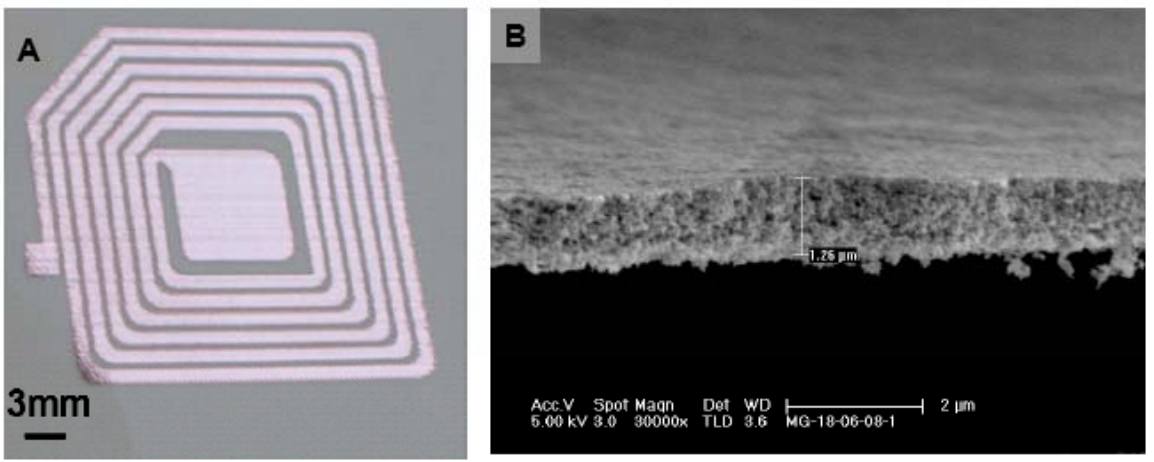

Fig. (14). RFID antenna printed onto photo paper with the use of aqueous dispersion of Cu/Ag core/shell nanoparticles (A) and SEM image of the cross-section of the printed track (B). (Fig. 14A reproduced with permission from Grouchko M, Kamyshny A, Magdassi S. J Mater Chem 2009; 19:3057-3062, The Royal Society of Chemistry). 
Although $\mathrm{Cu}$ and $\mathrm{Al}$ based inks are less developed or have yet to be developed for the latter metal, the understanding and progress made with Ag-based inks should be translatable to $\mathrm{Cu}$ and $\mathrm{Al} \mathrm{MC}$ inks despite the higher challenge of dealing with the greater oxophilic nature of both metals. It is likely that a combination of nanoparticles and MCs formulated as inks with the help of fast yet low temperature sintering techniques will allow the realization of high performing $\mathrm{Cu}$ and $\mathrm{Al}$ inks in the near future.

\section{ACKNOWLEDGEMENT}

This work was supported by the European Commission FP7 through Collaborative project LOTUS, Project Number 248816.

\section{REFERENCES}

[1] Nir MM, Zamir D, Haymov I, et al. Electrically conductive inks for inkjet printing. In: Magdassi S, Ed. The chemistry of inkjet inks. New Jersey-London-Singapore: World Scientific 2010; pp. 225-54.

[2] Subramanian V. Printed electronics. In: Magdassi S, Ed. The chemistry of inkjet inks. New Jersey-London-Singapore: World Scientific 2010; pp. 283-317.

[3] Mallory GO, Hajdu JB, Ed. Electroless plating: fundamental \& applications. New York: Noyes Publishing/William Andrew Publishing 1990.

[4] Ahn BY, Duoss EB, Motala MJ, et al. Omnidirectional printing of flexible, stretchable, and spanning silver microelectrodes. Science 2009; 323: 1590-3.

[5] Lewis JA, Ahn BY, Duoss EB. Metal nanoparticle ink. WO2010040034A2, April 8, 2010.

[6] Hudd A. Inkjet printing technologies. In: Magdassi S., Ed. The Chemistry of Inkjet Inks. New Jersey-London-Singapore: World Scientific 2010; pp. 3-18.

[7] Calvert P. Inkjet printing for materials and devices. Chem Mater 2001; 13: 3299-3305.

[8] Ryu B-H, Choi Y, Park H-S, et al. Synthesis of highly concentrated silver nanosol and its application to inkjet printing. Colloids Surf A 2005; 270-271: 345-351.

[9] De Gans B-J, Duineveld PC, Schubert US. Inkjet printing of polymers: state of the art and future developments. Adv Mater 2004; 16: 203-13.

[10] Deravi LF, Wright DW, Sumerel JL. Printing bioinks with technologically relevant applications. In: Magdassi S, Ed. The Chemistry of Inkjet Inks. New Jersey-London-Singapore: World Scientific 2010; pp. 269-82.

[11] Napadensky E. Inkjet 3D printing. In: Magdassi S, Ed. The Chemistry of Inkjet Inks. New Jersey-London-Singapore: World Scientific 2010; pp. 255-67.

[12] Fuller SB, Wilhelm EJ, Jacobson JM. Ink-jet printed nanoparticles microelectromechanical systems. J Microelectromech Syst 2002; 11: 54-60.

[13] Gamerith S, Klug A, Scheiber H, Scherf U, Moderegger E, List EJW. Direct ink-jet printing of $\mathrm{Ag}-\mathrm{Cu}$ nanoparticle and $\mathrm{Ag}$ precursor based electrodes for OFET applications. Adv Funct Mater 2007; 17: 3111-8.

[14] Rivkin T, Curtis CJ, Miedaner A, Alleman J, Schulz DL, Ginley DS. Copper and silver inks for ink jet printing. Electrochem Soc Proc 2001; 27: 80-9.

[15] Forrest SR. The path to ubiquitous and low-cost organic electronic appliances on plastic. Nature 2004; 428: 911-8.

[16] Ko SH, Pan H, Grigoropoulos CP, Luscombe CK, Fréchet JMJ, Poulikakos D. All-inkget-printed flexible electronics fabrication on a polymer substrate by low-temperature high-resolution selective laser sintering of metal nanoparticles. Nanotechnology 2007; 18: $345202(1-8)$

[17] Van Osch THJ, Perelaer J, De Laat AWM, Schubert US. Inkjet printing of narrow conductive tracks on untreated polymeric substrates. Adv Mater 2008; 20: 343-5.

[18] Perelaer J, Klokkenburg M, Hendriks CE, Schubert US. Microwave flash sintering of inkjet-printed silver tracks on polymer substrates. Adv Mater 2009; 21: 4830-4.
[19] Magdassi S, Grouchko M, Kamyshny A. Conductive inkjet inks for plastic electronics: air stable copper nanoparticles and room temperature sintering. NIP25 and Digital Fabrication. Tech Program Proc 2009: pp. 611-3.

[20] Magdassi S. Ink requirements and formulations guidelines. In: Magdassi S, Ed. The chemistry of inkjet inks. New Jersey-LondonSingapore: World Scientific 2010; pp. 19-41.

[21] Schefflan R, Kovenklioglu S, Kalyon D, Mezger M, Leng M. Formation of aluminum nanoparticles upon condensation from vapor phase for energetic applications. J Energ Mater 2006; 24: 141-56.

[22] Kwon Y-S, Gromov AA, Strokova JI. Passivation of the surface of aluminum nanopowders by protective coatings of the different chemical origin. Appl Surf Sci 2007; 253: 5558-64.

[23] Toshima N, Yonezawa T. Bimetallic nanoparticles - novel materials for chemical and physical applications. New J Chem 1998; 22: 1179-201.

[24] Grouchko M, Kamyshny A, Magdassi S. Formation of air-stable copper-silver core-shell nanoparticles for inkjet printing. J Mater Chem 2009; 19: 3057-62.

[25] Wu S-H, Chen D-H. Synthesis of high-concentration Cu nanoparticles in aqueous CTAB solution. J Colloid Interface Sci 2004; 273 : $165-9$.

[26] Song X, Sun S, Zhang W, Yin Z. A method for the synthesis of spherical copper nanoparticles in the organic phase. J Colloid Interface Sci 2004; 273: 463-9.

[27] Jouet RJ, Carney JR, Granholm RH, Sandusky HW, Warren AD. Preparation and reactivity analysis of novel perfluoroalkyl coated aluminium nanocomposites. Mater Sci Technol 2006; 22: 422-9.

[28] Campbell T, Kalia RK, Nakano A, Vashishta P. Dynamics of oxidation of aluminum nanoclusters using variable charge moleculardynamics simulations on parallel computers. Phys Rev Lett 1999; 82: 4866-9.

[29] Foley TJ, Johnson CE, Higa KT. Inhibition of oxide formation on aluminum nanoparticles by transition metal coating. Chem Mater 2005; 17: 4086-91

[30] Buffat Ph, Borel J-P. Size effect on the melting temperature of gold particles. Phys Rev A 1976; 13: 2287-98.

[31] Dick K, Dhanasekaran T, Zhang Z, Meisel D. Size-dependent melting of silica-encapsulated gold nanoparticles. J Am Chem Soc 2002; 124: 2312-7.

[32] Sheel DW, Brook LA, Yates HM. Controlled nanostructured silver coated surfaces by atmospheric pressure chemical vapour deposition. Chem Vapor Depos 2008; 14: 14-24.

[33] Wu J-T, Hsu L-C, Tsai M-H, Hwang W-S. Conductive silver patterns via ethylene glycol vapor reduction of ink-jet printed silver nitrate tracks on a polyimide substrate. Thin Solid Films 2009; 517: 5913-7.

[34] Kim H-S, Dhage SR, Shim D-E, Hahn HT. Intense pulsed light sintering of copper nanoink for printed electronics. Appl Phys A 2009; 97: 791-8.

[35] Bieri NR, Chung J, Poulikakos D, Grigoropoulos CP. Manufacturing of nanoscale thickness gold lines by laser curing of a discretely deposited nanoparticles suspension. Superlattices Microstruct 2004; 35: 437-44.

[36] Perelaer J, De Gans B-J, Schubert US. Inkjet printing and microwave sintering of conductive silver tracks. Adv Mater 2006; 18: 2101-4.

[37] Reinhold I, Hendriks CE, Eckardt R, et al. Argon plasma sintering of inkjet printed silver tracks on polymer substrates. J Mater Chem 2009; 19: 3384-8.

[38] Ko H, Jhin J, Byun D, Lee J, Park D. Copper thin films on PET prepared at ambient temperature by ECR-CVD. IEEE Trans Compon Packag Technol 2005; 28: 781-4.

[39] Allen ML, Aronniemi M, Mattila T, et al. Electrical sintering of nanoparticle structures. Nanotechnology 2008; 19: 175201 (1-4).

[40] Magdassi S, Grouchko M, Berezin O, Kamyshny A. Triggering the sintering of silver nanoparticles at room temperature. ACS Nano 2010; 4: 1943-8.

[41] Tretyakov YD, Lukashin AV, Eliseev AA. Synthesis of functional nanocomposites based on solid-phase nanoreactors. Russ Chem Rev 2004; 73: 899-921.

[42] Kimura K. Formation in gas phases. In: Schick MJ, Hybbard AT, Eds. Fine particles. Synthesis, characterization, and mechanisms of growth (Surf Sci Ser v. 92). New York-Basel: Marcel Dekker 2000; pp. 513-50. 
[43] Backman U, Jokiniemi JK, Auvinen A, Lechtinen KEJ. The effect of boundary conditions on gas-phase synthesized silver nanoparticles. J Nanopart Res 2002; 4: 325-35.

[44] Harfenist SA, Wang ZL, Whetten RL, Vezmar I, Alvarez MM. Three-dimensional hexagonal close-packed superlattice of passivated Ag nanocrystals. Adv Mater 1997; 9: 817-22.

[45] Fedushchak TA, Ermakov AE, Uimin MA, et al. The physicochemical properties of the surface of copper nanopowders prepared by the electroexplosion and gas-phase methods. Russ J Phys Chem A 2008; 82: 608-11.

[46] Henglein A. Physicochemical properties of small metal particles in solution: "microelectrode" reactions, chemisorption, composite metal particles, and the atom-to-metal transition. J Phys Chem 1993; 97: 5457-71.

[47] Mafune F, Kohno J, Takeda Y, Kondow T, Sawabe H. Formation and size control of silver nanoparticles by laser ablation in aqueous solution. J Phys Chem B 2000; 104: 9111-17.

[48] Chen Y-H, Yeh C-S. Laser ablation method: use of surfactants to form the dispersed Ag nanoparticles. Colloids Surf A 2002; 197: 133-9.

[49] Pitkethly MJ. Nanomaterials-the driving force. Mater Today 2004; 7: pp. 20-29.

[50] Kamyshny A, Magdassi S. Nanoparticles in confined structures: formation and application. In: Tadros TF, Ed. Colloid stability: the role of surface forces. Part I. Weinheim: Wiley-VCH 2007; pp. 207-33.

[51] Bönnemann H, Richards RM. Nanoscopic metal particles - synthetic methods and potential applications. Eur J Inorg Chem 2001; pp. 2455-80.

[52] Liz-Marzán LM. Nanometals: formation and color. Materials Today 2004; 7: 26-31.

[53] Schmid G. Metals. In: Klabunde KJ, Ed. Nanoscale Materials in Chemistry. New York: John Wiley \& Sons 2001; pp. 15-59.

[54] Toshima N. Reactions in homogeneous solutions. In: Schick MJ, Hybbard AT, Eds. Fine particles. Synthesis, characterization, and mechanisms of growth (Surf Sci Ser v. 92). New York-Basel: Marcel Dekker 2000; pp. 430-59.

[55] Fiévet F. Polyol process. In: Schick MJ, Hybbard AT, Eds. Fine particles. Synthesis, characterization, and mechanisms of growth (Surf Sci Ser v. 92). New York-Basel: Marcel Dekker 2000; pp. 460-496.

[56] Magdassi S, Grouchko M, Kamyshny A. Colloidal dispersion of metal nanoparticles: formation and functional properties. In: Hidalgo-Alvarez R. Ed. Structure and functional properties of colloidal systems (Surf Sci Ser v. 146). Boca Raton-London-New York: CRC Press 2010; pp. 339-65.

[57] Dupont J, Fonseca GS, Umpierre AP, Fichtner PFP, Teixeira SR. Transition-metal nanoparticles in imidazolium ionic liquids: recycable catalysis for biphasic hydrogenation reactions. J Am Chem Soc 2002; 124: 4228-9.

[58] Ott LS, Cline ML, Deetlefs M, Seddon KR, Finke RG. Nanoclusters in ionic liquids: evidence for $\mathrm{N}$-heterocyclic carbene formation from imidazolium-based ionic liquids detected by ${ }^{2} \mathrm{H}$ NMR. J Am Chem Soc 2005; 127: 5758-9.

[59] Kamyshny A, Magdassi S. Aqueous dispersions of metallic nanoparticles: preparation, stabilization and application. In: Starov V, Ed. Nanoscience: colloidal and interfacial aspects. Boca RatonLondon-New York: CRC Press 2010; pp. 747-78.

[60] Teranishi T. Metallic colloids. In: Somasundaram P, Ed. Encyclopedia of surface and colloid science. New York: Marcel Dekker 2002; pp. 3314-27.

[61] Sun Y, Xia Y. Gold and silver nanoparticles: a class of chromophores with color tunable in the range from 400 to $750 \mathrm{~nm}$. Analyst 2003; 128: 686-91.

[62] Goia DV, Matijević E. Preparation of monodispersed metal particles. New J Chem 1998; 22: 1203-15.

[63] Goia DV Preparation and formation mechanisms of uniform metallic particles in homogeneous solutions. J Mater Chem 2004; 14 : 451-8.

[64] Suber L, Sondi I, Matijević E, Goia DV. Preparation and the mechanisms formation of silver particles of different morphologies in homogeneous solutions. J Colloid Interface Sci 2005; 288: 48995.

[65] Murphy CJ, Sau TK, Gole AM, et al. Anisotropic metal nanoparticles: synthesis, assembly, and optical applications. J Phys Chem B 2005; 109: 13857-70.
[66] Khanna PK, Gaikwad S, Adhyapak PV, Singh N, Marimuthu R. Synthesis and characterization of copper nanoparticles. Mater Lett 2007; 61: 4711-4.

[67] Zhang X, Zhang D, Ni X, Zheng H. One-step preparation of copper nanorods with rectangular cross sections. Solid State Commun 2006; 139: 412-4.

[68] Liz-Marzán LM, Lado-Touriño I. Reduction and stabilization of silver nanoparticles in ethanol by nonionic surfactants. Langmuir 1996; 12: 3585-9.

[69] Pastoriza-Santos I, Liz-Marzán LM. Synthesis of silver nanoprisms in DMF. Nano Lett 2002; 2: 903-5.

[70] Lee KJ, Jun BH, Kim TH, Joung J. Direct synthesis and inkjetting of silver nanocrystals toward printed electronics. Nanotechnology 2006; 17: 2424-8.

[71] Cho S-N, Oh S-I, Cho H-J. Metal nanoparticles and method for manufacturing thereof. US20070056402A1, March 15, 2007.

[72] Curtis AC, Duff DG, Edwards PP, et al. Preparation and structural characterization of an unprotected copper sol. J Phys Chem 1988; 92: 2270-5.

[73] Wang Y, Chen P, Liu M. Synthesis of well-defined copper nanocubes by a one-pot solution process. Nanotechnology 2006; 17: 6000-6.

[74] Mott D, Galkowski J, Wang L, Luo J, Zhong C-J. Synthesis of size-controlled and shaped copper nanoparticles. Langmuir 2007; 23: $5740-5$.

[75] Shim I-K, Oh Y-S, Joung J-W. Core-shell structure metal nanoparticles and its manufacturing method. US20070212562A1, September 13, 2007.

[76] Bonet F, Delmas V, Grugeon S, Herrera Urbina R, Silvert P-Y, Tekaia-Elhsissen K. Synthesis of monodisperse Au, Pt, Pd, Ru and Ir nanoparticles in ethylene glycol. Nano Struct Mater 1999; 11: 1277-84.

[77] Wiley B, Sun Y, Mayers B, Xia Y. Shape-controlled synthesis of metal nanostructures: the case of silver. Chem Eur J 2005; 11; 45463.

[78] Silvert P-Y, Herrera-Urbina R, Duvauchelle N, Vijayakrishnan V, Elhsissen KT. Preparation of colloidal silver dispersions by the polyol process. Part 1 - synthesis and characterization. J Mater Chem 1996; 6: 573-7.

[79] Kapoor S. Preparation, characterization, and surface modification of silver nanoparticles. Langmuir 1998; 14: 102125.

[80] Kapoor S. Effect of ligands on the redox reactions of silver metal clusters. Langmuir 1999; 15: 4365-9.

[81] Henglein A, Giersig M. Formation of colloidal silver nanoparticles: capping action of citrate. J Phys Chem B 1999; 103: 9533-9.

[82] Choi S-H, Lee S-H, Hwang Y-M, Lee K-P, Kang H-D. Interaction between the surface of the silver nanoparticles prepared by $\gamma$ irradiation and organic molecules containing thiol group. Radiat Phys Chem 2003; 67: 517-21.

[83] Joshi SS, Patil SF, Iyer V, Mahumuni S. Radiation induced synthesis and characterization of copper nanoparticles. Nanostruct Mater 1998; 10: 1135-44.

[84] Rodrogues-Sanchez L, Blanco MC, Lopez-Quintela MA. Electrochemical synthesis of silver nanoparticles. J Phys Chem B 2000; 104: 9683-8

[85] Starowicz M, Stypuła B, Banaś J. Electrochemical synthesis of silver nanoparticles. Electrochem Commun 2006; 8: 227-30.

[86] Ma H, Yin B, Wang S, et al. Synthesis of silver and gold nanoparticles by a novel electrochemical method. Chem Phys Chem 2004; 5: 68-75.

[87] Raja M, Shuba J, Ali FB, Ryu SH. Synthesis of copper nanoparticles by electroreduction process. Mater Manufact Process 2008; 23 : 782-5.

[88] Yin B, Ma H, Wang S, Chen S. Electrochemical synthesis of silver nanoparticles under protection of poly(N-vinylpyrrolidone). J Phys Chem B 2003; 107: 8898-904.

[89] Dhas NA, Raj CP, Gedanken A. Synthesis, characterization and properties of metallic copper nanoparticles. Chem Mater 1998; 10: 1446-52.

[90] Salkar RA, Jeevanandam P, Aruna ST, Koltypin Y, Gedanken A. The sonochemical preparation of amorphous silver nanoparticles. J Mater Chem 1999: 9: 1333-5.

[91] Yang G-W, Li H. Sonochemical synthesis of highly monodispersed and size controllable Ag nanoparticles in ethanol solution. Mater Lett 2008; 62: 2189-91. 
[92] Zhu J, Liu S, Palchik O, Koltypin Y, Gedanken A. Shapecontrolled synthesis of silver nanoparticles by pulse sonoelectrochemical methods. Langmuir 2000; 16: 6396-9.

[93] Jiang L-P, Wang A-N, Zhao Y, Zhang J-R, Zhu J-J. A novel route for the preparation of monodisperse silver nanoparticles via a pulsed sonoelectrochemical technique. Inorg Chem Commun 2004; 7: 506-9.

[94] Tang S, Meng X, Lu H, Zhu S. PVP-assisted sonoelectrochemical growth of silver nanostructures with various shapes. Mater Chem Phys 2009; 116: 464-8.

[95] Haas I, Shanmugam S, Gedanken A. Pulsed sonoelectrochemical synthesis of size-controlled copper nanoparticles stabilized by poly (N-vinylpyrrolidone). J Phys Chem B 2006; 110: 16947-52.

[96] Nagasawa H, Maruyama M, Maruyama M, Komatsu T, Isoda S, Kobayashi T. Physical characteristics of stabilized silver nanoparticles formed using a new thermal-decomposition method. Phys Stat Sol A 2002; 191: 67-76.

[97] Lee Y-I, Cho H-J. Metal nanoparticles and method for producing the same. US20070018140A1, January 25, 2007.

[98] Hambrock J, Becker R, Birkner A, Weiß J, Fischer RA. A nonaqueous organometallic route to highly monodispersed copper nanoparticles using $\left[\mathrm{Cu}\left(\mathrm{OCH}(\mathrm{Me}) \mathrm{CH}_{2} \mathrm{NMe}_{2}\right)_{2}\right]$. Chem Commun 2002; 68-9.

[99] Kim YH, Lee DK, Jo BG, Jeong JH, Kang YS. Synthesis of oleate capped $\mathrm{Cu}$ nanoparticles by thermal decomposition. Colloids Surf A 2006; 284-285: 364-8.

[100] Hirai H, Wakabayashi H, Komiyama M. Preparation of polymerprotected colloidal dispersions of copper. Bull Chem Soc Jpn 1986; 59: 367-72.

[101] Huang HH, Yan FQ, Kek YM, et al. Synthesis, characterization, and nonlinear optical properties of copper nanoparticles. Langmuir 1997; 13: 172-5.

[102] Harada T, Fujiwara H. Formation of rod shape secondary aggregation of copper nanoparticles in aqueous solution of sodium borohydride with stabilizing polymer. J Phys Conf Ser 2007; 61: 394-8.

[103] Patakfalvi R, Virányi Z, Dékány I. Kinetics of silver nanoparticle growth in aqueous polymer solutions. Colloid Polym Sci 2004: 283: 299-305.

[104] Chou K-S, Lai Y-S. Effect of polyvinyl pyrrolidone molecular weight on the formation of nanosized silver colloids. Mater Chem Phys 2004; 83: 82-8.

[105] Lee H-H, Chou K-S, Huang K-C. Inkjet printing on nanosized silver colloids. Nanotechnology 2005; 16: 2436-41.

[106] Chang J-S, Lee Y-P, Wang R-C. Optimization of nanosized silver particles synthesis via experimental design. Ind Eng Chem Res 2007; 46: 5591-9.

[107] Patakfalvi R, Papp S, Dékány I. The kinetics of homogeneous nucleation of silver nanoparticles stabilized by polymers. $\mathbf{J}$ Nanopart Res 2007; 9: 353-64.

[108] Wu C, Mosher BP, Zeng T. One-step green route to narrowly dispersed copper nanocrystals. J Nanopart Res 2006; 8: 965-9.

[109] Sarkar A, Mukherjee T, Kapoor S. PVP-stabilized copper nanoparticles: a reusable catalyst for "click" reaction between terminal alkynes and azides in nonaqueous solvents. J Phys Chem C 2008; 112: 3334-40.

[110] Kim D, Jeong S, Moon J. Synthesis of silver nanoparticles using the polyol process and the influence of precursor injection. Nanotechnology 2006; 17: 4019-24.

[111] Lee Y, Choi J-R, Lee KJ, Stott NE, Kim D. Large-scale synthesis of copper nanoparticles by chemically controlled reduction for application of inkjet-printed electronics. Nanotechnology 2008; 19 : 415604(1-7).

[112] Kim D, Moon J. Highly conductive ink jet printed films of nanosilver particles for printable electronics. Electrochem Solid-State Lett 2005; 8: J30-3.

[113] Park BK, Kim D, Jeong S, Moon J, Kim JS. Direct writing of copper conductive patterns by ink-jet printing. Thin Solid Films 2007; 515: 770611.

[114] Park BK, Jeong S, Kim D, Moon J, Lim S, Kim JS. Synthesis and size control of monodisperse copper nanoparticles by polyol method. J Colloid Interface Sci 2007; 311: 417-24.

[115] Woo K, Kim D, Kim JS, Lim S, Moon J. Ink-jet printing of Cu-Agbased highly conductive tracks on a transparent substrate. Langmuir 2009; 25: 429-33.
[116] Magdassi S, Bassa A, Vinetsky Y, Kamyshny A. Silver nanoparticlesas pigments for water-based ink-jet inks. Chem Mater 2003; 15: $2208-17$.

[117] Sondi I, Goia DV, Matijević E. Preparation of highly concentrated stable dispersions of uniform silver nanoparticles. J Colloid Interface Sci 2003; 260: 75-81.

[118] Kamyshny A, Ben-Moshe M, Aviezer S, Magdassi S. Ink-jet printing of metallic nanoparticles and microemulsions. Macromol Rapid Commun 2005; 26: 281-8.

[119] Ung T, Giersig M, Dunstan D, Mulvaney P. Spectroelectrochemistry of collodal silver. Langmuir 1997; 13: 1773-82.

[120] Grouchko M, Kamyshny A, Ben-Ami K, Magdassi S. Synthesis of copper nanoparticles catalyzed by pre-formed silver nanoparticles. J Nanopart Res 2009; 11: 713-6.

[121] Li W, Jia QX, Wang H-L. Facile synthesis of metal nanoparticles using conductive polymer colloids. Polymer 2006; 47: 23-6.

[122] Jeong S, Woo K, Kim D, et al. controlling the thickness of the surface oxide layer on $\mathrm{Cu}$ nanoparticles for the fabrication of conductive structures by inkjet printing. Adv Func Mater 2008; 18: 679-86.

[123] Kim JS, Moon JH, Jeong SH, Kim DJ, Park BK. Copper nanoparticles, method of preparing the same, and method of forming copper coating film using the same. US20070180954A1, August 9 , 2007.

[124] Kanninen P, Johans C, Merta J, Kontturi K. Influence of ligand structure on the stability and oxidation of copper nanoparticles. J Colloid Interface Sci 2008; 318: 88-95.

[125] Luechinger NA, Athanassiou EK, Stark WJ. Graphene-stabilized copper nanoparticles as an air-stable substitute for silver and gold in low-cost ink-jet printable electronics. Nanotechnology 2008; 19 : 445201(1-6).

[126] Bradley JS, Schmid G. Noble metal nanoparticles. In: Schmid G, Ed. Nanoparticles: from theory to applications. Weinheim: WileyVCH Verlag GmbH \& Co. Kga A 2004; pp. 186-238.

[127] Pal T, Sau TK, Jana NR. Reversible formation and dissolution of silver nanoparticles in aqueous surfactant media. Langmuir 1997; 13: 1481-5.

[128] Van Hyning DL, Zukoski CF. Formation mechanisms and aggregation behavior of borohydride reduced silver particles. Langmuir 1998; 14: 7034-46.

[129] Cliffel DE, Zamborini FP, Gross SM, Murray RW. Mercaptoammonium-monolayer-protected, water-soluble gold, silver, and palladium clusters. Langmuir 2000; 16: 9699702.

[130] Jiang X, Xie Y, Lu J, Zhu L, He W, Qian Y. Preparation, characterization, and catalytic effect of $\mathrm{CS}_{2}$-stabilized silver nanoparticles in aqueous solution. Langmuir 2001; 17: 3795-9.

[131] Heard UM, Griezer F, Barraclough CG. The characterization of Ag sols by electron microscopy, optical absorption, and electrophoresis. J Colloid Interface Sci 1983; 93: 545-55.

[132] Munro CH, Smith WE, Garner M, Clarkson J, White PC. Characterization of the surface of citrate-reduced colloid optimized for use as a substrate for surface-enhanced resonance Raman scattering. Langmuir 1995; 11: 3712-20.

[133] Rivas L, Sanchez-Cores S, Garcia-Ramos JV, Morcillo G. Growth of silver colloidal particles obtained by citrate reduction to increase the Raman enhancement factor. Langmuir 2001; 17: 574-7.

[134] Tripathi GNR, Clements M. Adsorption of 2-mercaptopyrimidine on silver nanoparticles in water. J Phys Chem B 2003; 107: 11125 32.

[135] Mayer ABR, Grebner W, Wannemacher R. Preparation of silverlatex composites J Phys Chem B 2000; 104: 7278-85.

[136] Balantrapu K, Goia DV. Siver nanoparticles for printable electronics and biological application. J Mater Res 2009; 24: 1828-36.

[137] Nickel U, Zu Caztel A, Pöppl K, Schneider S. A silver colloid produced by reduction with hydrazine as support for highly sensitive surface-enhanced Raman spectroscopy. Langmuir 2000; 16: 9087-91.

[138] Zhang Z, Han M. Template-directed growth from small clusters into uniform silver nanoparticles. Chem Phys Lett 2003; 374: 91-4.

[139] Rockenberger J, Zurcher F, Haubrich S, Sleiman N. Nanoparticle synthesis and the formation of inks therefrom. US6878184, April $12,2005$.

[140] Jun B-H, Lee K-J, Cho H-J, Joung J-W. Method for producing silver nanoparticles and conductive ink. US20090223410A1, September 10, 2009. 
[141] Li Y, Lee JS-C, Pan H, Smith PF, Mahabadi HK. Metal nanoparticles stabilized with a carboxylic acid-organoamine complex. US20090148600A1, June 11, 2009.

[142] Li Y, Wu Y, Pan H, Liu P, Smith PF, Mahabadi HK. Stabilized metal nanoparticles and methods for depositing conductive features using stabilized metal nanoparticles. US20090181183A1, July 16, 2009.

[143] Vanheusden K, Kunze K, Kim H, et al. Metal nanoparticle compositions. WO2006076613A3, July 20, 2006.

[144] Lee J-T, Heo S-Y, Kim M-S, Kim H-S. Ink for ink jet printing and method for preparing metal nanoparticles used therein. WO2008038867A1, April 3, 2008.

[145] Kim JS, Lim S-K, Moon JH, Jeong SH, Kim DJ, Wo K-H. Method of manufacturing a metal nanoparticle, conductive ink composition having the metal nanoparticles and method of forming a conductive pattern using the same. US20080241391A1, October 2, 2008.

[146] Magdassi S, Kamyshny A, Aviezer S, Grouchko M. Aqueousbased dispersions of metal nanoparticles. WO2006072959A1, July 132006.

[147] Keskinen J, Ruuskanen P, Karttunen M, Hannula S-P. Synthesis of silver power using a mechanochemical process. Appl Organomet Chem 2001; 15: 393-5.

[148] Lee J, Ahn J-G, Tung LM, et al. Preparation of Ag powders by mechanochemical reaction in $\mathrm{AgCl}-\mathrm{Cu}$ system. TMS Lett 2006; 3 : 41-2.

[149] Khasin E. Method of producing high-purity ultra-fine metal powder. US5476535, December 19, 1995.

[150] Garbar A, De La Vega F, Matzner E. A method for the production of highly pure metallic nano-powders and nano-powders produced thereby. WO2004000491A2, December 31, 2003.

[151] Garbar A, Lekhtman D, De La Vega F, Magdassi S, Kamyshny A, Kahana F. Ink jet printable compositions. WO2006/030286A1, March 23, 2006.

[152] Oriakhi CO. Metallic inkjet ink and method for forming the same. US7615111, November 10, 2009.

[153] Chung K-C, Cho H-N, Gong M-S, et al. Conductive inks and manufacturing thereof. US7691294B2, April 6, 2010.

[154] Itoh D, Izumitani A, Hata N, Matsuba Y, Murata K, Yokoyama H. Metal nano particle liquid dispersion capable of being sprayed in fine particle form and being applied in laminated state. EP1666175A1, September 10, 2004.

[155] Okada I, Shimada K. Metallic colloidal solution and inkjet-use metallic ink. US7608203B2, October 27, 2009.

[156] Perelaer J, De Laat AWM, Hendriks CE, Schubert US. Inkjetprinted silver tracks: low temperature curing and thermal stability investigation. J Mater Chem 2008; 18: 3209-15.

[157] Kim D, Jeong S, Park BK, Moon J. Direct writing of silver conductive patterns: improvement of film morphology and conductance by controlling solvent compositions. Appl Phys Lett 2006; 89: 264101(1-3).

[158] Li X, Li Y, Laxton PB, Roundhill DM, Arimura H. Additives and modifiers for solvent- and water-based metallic conductive inks. US20090242854A1, October 3, 2009.

[159] Chopra N, Kazmaier PM, Lalisse DJ, Smith PF. Synthesis of conductive metal markings for chipless RFID applications. US20090226605A1, September 10, 2009.

[160] Advanced curing for printed electronics. Available from: http://www.novacentrix.com/ images/downloads/PF_Brochure_ 4pg.pdf.

[161] Li Z, Rahtu A, Gordon RG. Atomic layer deposition of ultrathin copper metal films from a liquid copper (I) amidinate precursor. J Electrochem Soc 2006; 153: C787-94.

[162] Lim BS, Rahtu A, Gordon RG. Atomic layer deposition of transition metals. Nat Mater 2003; 2: 749-54.

[163] Delgado S, Corripio D, Moreno C. Synthesis and characterization of alkenes $\beta$-diketonate copper(I) complexes. Inorg Chim Acta 2004; 357: 3205-10.

[164] Teichgraeber J, Dechert S, Meyer F. Dicopper (I) oxalate complexes as molecular precursors for the deposition of copper compounds. J Organomet Chem 2005; 690: 5255-63.

[165] Pirolli L, Teplyakov AV. Adsorption and thermal chemistry of 1,1,1,5,5,5,-hexafluoro-2,4-pentadione (hfacH) and hexafluoroacetylacetonate) $\mathrm{Cu}$ (vinyltrimethylsilane) ((hfac)Cu(VTMS)) on TiCN-covered Si(100) surface. Surf Sci 2007; 601: 155-64.
[166] Senocq F, Turgambaeva A, Prud'homme N, et al. Thermal behavior of $\mathrm{CpCuPEt}_{3}$ in gas phase and $\mathrm{Cu}$ Thin films processing. Surf Coat Technol 2007; 201: 9131-4

[167] Tran PD, Doppelt P. Evolution of a novel fluorine free copper (I) precursor for Cu CDV. Surf Coat Technol 2007; 201: 9066-70.

[168] Turgambaeva AE, Krisyuk VV, Stabnikov P, Igumenov I. Mass spectrometric study of the thermal decomposition mechanism of vapor of 2,2,6,6-tetramethyl-3-iminohep[tane-5-one and its copper(II) complex. J Organomet Chem 2007; 692: 5001-6.

[169] Szymańska IB, Piszczek P, Szłyk E. Gas phase studies of new copper (I) carboxylates compounds with vinylsilanes and their application in Chemical Vapor Deposition (CVD). Polyhedron 2009; 28: 721-8.

[170] Fragalá ME, Malandrino G, Puglisi O. Synthesis, X-ray structure, and characterization of $\mathrm{Ag}$ (hfa)-tetraglyme [hfa=hexafluoroacetylacetonate]: a novel adduct for the fabrication of metallic silver based films via in situ self reduction. Chem Mater 2000; 12: 290-3.

[171] Edwards DA, Mahon MF, Molloy KC, Ogrodnik V. Aerosolassisted chemical vapour deposition of silver films from adducts of functionalised silver carboxylates. J Mater Chem 2003; 13: 563-70.

[172] Piszczek P, Szłyk E, Chaberski M, et al. Characterization of silver trimethylacetate complexes with tertiary phosphines as CVD precursors of thin silver films. Chem Vapor Depos 2005; 11: 53-9.

[173] Chi Y, Lay E, Chou T-Y, Song Y-H, Carty AJ. Deposition of silver thin films using the pyrazolate complex $\left[\mathrm{Ag}\left(3,5-\left(\mathrm{CF}_{3}\right)_{2} \mathrm{C}_{3} \mathrm{HN}_{2}\right)\right]_{3}$. Chem Vapor Depos 2005; 11: 206-12.

[174] Haase T, Kohse-Höinghaus K, Bahlawane N, Djiele P, Jakob A Lang H. CVD with tri- ${ }^{\mathrm{n}}$ butylphosphine silver(I) complexes: mass spectrometric investigations and depositions. Chem Vapor Depos 2005; 11: 195-205.

[175] Meijboom R, Bowen RJ, Berners-Price SJ. Coordination complexes of silver (I) with tertiary phosphine and related ligands. Coord Chem Rev 2009; 253: 325-42.

[176] Grodzicki A, Łakomska I, Piszczek P, Szymańska I, Szłyk E. Copper(I), silver(I) and gold(I) carboxylate complexes as precursors in chemical vapour deposition of thin metallic films. Coord Chem Rev 2005; 249: 2232-58.

[177] Zhang Y-Y, Wang Y, Tao X, Wang N, Shen Y-Z. Synthesis and characterization of organophosphine/phosphite stabilized silver (I) methanesulfonates: crystal structures of $\left[\mathrm{Ph}_{3} \mathrm{PAgO}_{3} \mathrm{SCH}_{3}\right]$ and $\left[\left(\mathrm{Ph}_{3} \mathrm{P}\right)_{2} \mathrm{AgO}_{3} \mathrm{SCH}_{3}\right]$. Polyhedron 2008; 27: 2501-5.

[178] McCain MN, Schneider S, Salata MR, Marks TJ. Tris (phosphino)borato silver(I) complexes as precursors for metallic silver aerosol-assisted chemical vapor deposition. Inorg Chem 2008; 47: 2534-42.

[179] Becker R, Devi A, Weiß J, et al. A study on the metal-organic CVD of pure copper films from low cost copper (II) dialkylamino2-propoxides: tuning the thermal properties of the precursor by small variations of the ligand. Chem Vapor Depos 2003; 9: 149-56.

[180] Park K-H, Marshall WJ. Remarkably volatile copper (II) complexes of $\mathrm{N}, \mathrm{N}$-unsymmetrically substituted 1,3-diketimines as precursors for $\mathrm{Cu}$ metal deposition via CVD or ALD. J Am Chem Soc 2005; 127: 9330-1.

[181] Mukhopadhyay S, Shalini K, Lakshmi R, Devi A, Shivashankar $\mathrm{SA}$. Metalorganic chemical vapor deposition of $\mathrm{Cu}$ films from bis (t-butyl-3-oxo-butanoato) copper (II): thermodynamic investigation and experimental verification. Surf Coat Technol 2002; 150: 20511 .

[182] Shahid, M, Tahir AA, Hamid M, et al. Copper (II) oligomeric derivatives for deposition of copper thin films. Eur J Inorg Chem 2009: 1043-50.

[183] Li Z, Barry ST, Gordon RG. Synthesis and characterization of copper (I) amidinates as precursors for atomic layer deposition (ALD) of copper metal. Inorg Chem 2005; 44: 1728-35.

[184] Coyle JP, Johnson PA, DiLabio GA, Barry ST, Müller J. Gas-phase thermolysis of guanidinate precursor of copper studied by matrix isolation, time-of-flight mass spectrometry, and computational chemistry. Inorg Chem 2010; 49: 2844-50.

[185] Tran PD, Allavena-Valette A, Kamous F, Doppelt P. Novel valuable fluorine free copper(I) precursors for copper chemical vapor deposition. Polyhedron 2009; 28: 4091-5.

[186] Pirolli L, Teplyakov AV. Molecular view of copper deposition chemistry: (hexafluoroacetylacetonate $(\mathrm{Cu}$ (vinyltrimethylsilane) on a Si(100)-2x1 surface. Surf Sci 2006; 600: 3313-20 
[187] Bahlawane N, Premkumar PA, Brechling A, Reiss G, KohseHöinghaus K. Alcohol-assisted CVD of silver using commercially available precursors. Chem Vapor Depos 2007; 13: 401-7.

[188] Bahlawane N, Premkumar PA, Onwuka K, Rott K, Reiss G, Kohse-Höinghaus K. Catalytically enhanced $\mathrm{H}_{2}$-free CVD of transition metals using commercially available precursors. Surf Coat Technol 2007; 201: 8914-8.

[189] Bahlawane N, Premkumar PA, Reilmann F, et al. CVD of conducting ultrafine copper films. J Electrochem Soc 2009; 156: D452-5.

[190] Lay E, Song Y-H, Chiu Y-C, et al. New CVD precursors capable of depositing copper metal under mixed $\mathrm{O}_{2} / \mathrm{Ar}$ atmosphere. Inorg Chem 2005; 44: 7226-33.

[191] Teng KF, Vest RW. Metallization of solar cells with ink jet printing and silver metallo-organic inks. IEEE Trans Compon Hybrids Manuf Technol 1988; 11: 291-7.

[192] Kodas TT, Hampden-Smith MJ, Atanassova P, et al. Low viscosity precursor compositions and methods for the deposition of conductive electronic features. WO2003032084A3, April 17, 2003.

[193] Dearden AL, Smith PJ, Shin D-Y, Reis N, Derby B, O'Brien P. A low curing temperature silver ink for use in ink-jet printing and subsequent production of conductive tracks. Macromol Rapid Commun 2005; 26: 315-8.

[194] Jun B-H, Oh S-I, Lee K-J. Conductive ink, preparation method thereof and conductive board. US2006437812A1, November 23, 2006.

[195] Curtis CJ, Schulz DL, Miedaner A, et al. Spray and inkjet printing of hybrid nanoparticle-metal-organic inks for $\mathrm{Ag}$ and $\mathrm{Cu}$ metallization. Mat Res Soc Symp Proc 2001; 676: Y8.6.1-6.

[196] Curtis CJ, Rivkin T, Miedaner A, et al. Metallizations by directwrite inkjet printing. Mat Res Soc Symp Proc 2002; 730: 79-84.

[197] Curtis CJ, Rivkin T, Miedaner A, et al. Spray and inkjet printing of hybrid nanoparticle-metal-organic inks for $\mathrm{Ag}$ and $\mathrm{Cu}$ metallization. NCPV Progr Rev Meeting Proc 2001: pp. 249-52.

[198] Smith PJ, Shin D-Y, Stringer JE, Derby B. Direct ink-jet printing and low temperature conversion of conductive silver patterns. J Mater Sci 2006; 41: 4153-8.

[199] Reinartz NM. Silver-containing ink. WO2006066033A1, June 22, 2006.

[200] Chung K-C, Cho H-N, Gong M-S, et al. Organic silver complexes, their preparation methods and their methods for forming thin layers. US20090120800A1, May 14, 2009.

[201] Xue FL, Liu Z, Su Y, Varahramyan K. Inkjet printed silver source/drain electrodes for low-cost polymer thin film transistors. Microelectronic Eng 2006; 83: 298-302.

[202] Ginley DS, Curtis CJ, Miedaner A, Van Hest MFAM, Kaydanova T. Metal inks. US20080003364A1, January 3, 2008.

[203] Wang Z, Wu W, Yang O, Li Y, Noh C-H. In-situ fabrication of flexible vertically integrated electronic circuits by inkjet printing. J Alloys and Compounds 2009; 486: 706-10.

[204] Perelaer J, Hendriks CE, de Laat AWM, Schubert US. One-step inkjet printing of conductive silver tracks on polymer substrates. Nanotechnology 2009; 20: 165303(1-5).

[205] Valeton JJP, Hermans K, Bastiaansen CWM, et al. Room temperature preparation of conductive silver features using spin-coating and inkjet printing. J Mater Chem 2010; 20: 543-6.

[206] Jakob A, Lang H, Baumann R, et al. Verfahren zur herstellung von elektrisch leitfähigen strukturen. EP2159270A1, August 28, 2008.

[207] Rozenberg GG, Bresler E, Speakman SP, Jeynes C, Steinke JHG. Patterned low temperature copper-rich deposits using inkjet printing. Appl Phys Lett 2002; 81: 5249-51.
[208] Jeynes C, Rozenberg GG, Speakman SP, Steinke JHG. A microbeam RBS analysis of low temperature direct-write inkjet deposited copper. Nucl Instrum Methods Phys Res Sect B 2002; 188: 141-5.

[209] Rozenberg GG, Steinke JHG. Synthesis and spectroscopic studies of novel $\beta$-diketonate copper(I) compounds and solid state structure of tetravinylsilane tetrakis copper(I) 1,1,1,5,5,5-hexafluoroacetylacetonate (TVST[Cu]hfac). Organometallics 2001; 20: 4001-5.

[210] Rickerby J, Simon A, Jeynes, C, Morgan TJ, Steinke JHG. 1,1,1,5,5,5-Hexafluoroacetylacetonate copper(I) poly(vinylsiloxane)s as precursors for copper direct-write. Chem Mater 2006; 18:2489-98.

[211] Barrière C, Alcaraz G, Margeat $\mathrm{O}$, et al. Copper nanoparticles and organometallic chemical liquid deposition (OMCLD) for substrate metallization. J Mater Sci 2008; 18: 3084-6.

[212] Curtis CJ, Miedaner A, Van Hest MFAM, Ginley DS. Printing aluminum films and patterned contacts using organometallic precursor inks. WO2009059273A2, May 7, 2009.

[213] Rockenberger J, Zurcher F, Guo W. Aluminum inks and methods of making the same, methods for depositing aluminum inks, and films by printing and/or depositing an aluminum ink. WO2010011974A1, January 28, 2010.

[214] Duerinckx F, Szlufcik J. Defect passivation of industrial multicrystalline solar cells based on PECVD silicon nitride. Solar Energy Mater. Solar Cells 2002; 72: 231-46.

[215] Schubert G, Huster F, Fath P. Physical understanding of printed thick-film front contacts of crystalline Si solar cells - review of existing models and recent developments. Solar Energy Mater. Solar Cells 2002; 90; 3399-406.

[216] Bottari FJ, Hanoka J, Sylva FW. Method of applying metallized contacts to a solar cell. US5151386, September 29, 1992.

[217] Baert KA, Roggen J, Nijs JF, Mertens RP. Amorphous-silicon solar cells with screen-printed metallization. IEEE Trans Electron Devices 1990; 37: 702-7.

[218] Curtis CJ, Miedaner A, Rivkin T, Alleman J, Schulz DL, Ginley DS. Direct write metallization for Ag and Al. Mat Res Soc Symp Proc 2000; 624: 59-64.

[219] Ginley DS, Kaydanova T, Miedaner A, Curtis C, Van Hest MFAM. Fabrication of contacts for silicon solar cells including printing burn through layers. WO2009059302A1, May 7, 2009.

[220] Wu Y, Li Y, Ong BS. A simple and efficient approach to a printable silver conductor for printed electronics. J Am Chem Soc 2007; 129: $1862-3$.

[221] Noguchi Y, Sekitani T, Yokota T, Someya T. Direct inkjet printing of silver electrodes on organic semiconductors for thin-film transistors with top contact geometry. Appl Phys Lett 2008; 93: 043303(1-3).

[222] Whiting GL, Arias AC. Chemically modified ink-jet printed silver electrodes for organic field-effect transistors. Appl Phys Lett 2009; 95: 253302(1-3).

[223] Sekitani T, Noguchi Y, Zschieschang U, Klauk H, Someya T. Organic transistors manufactured using inkjet technology with subfemtoliter accuracy. Proc Natl Acad Sci USA 2008; 105: 4976-80.

[224] Hong CM. Inkjet printed copper source/drain metallization for amorphous silicon thin-film transistors. IEEE Electron Device Lett 2000; 21: 384-6.

[225] Allen ML, Jaakkola K, Nummila K, Seppä H. Applicability of metallic nanoparticle inks in RFID applications. IEEE Trans Comp Packag Technol 2009; 32: 325-32. 